\title{
VEGETACIÓN DE LA SIERRA MADRE OCCIDENTAL, MÉXICO: UNA SÍNTESIS
}

\author{
M. Socorro González-Elizondo, Martha González-Elizondo, J. A. Tena-Flores, \\ Lizeth RuACHo-GonZÁlez E I. LORENA LÓPEZ-EnRíQueZ
}

Instituto Politécnico Nacional, Centro Interdisciplinario de Investigación para el Desarrollo Integral Regional, Unidad Durango, Sigma 119, Fracc. 20 de Noviembre II, 34220 Durango, Durango, México. Autor para la correspondencia: herbario_ciidir@yahoo.com.mx

\section{RESUMEN}

La Sierra Madre Occidental (SMO) es el complejo montañoso más grande de México, extendiéndose por casi $1200 \mathrm{~km}$ desde el noreste de Sonora $\left(30^{\circ} 35^{\prime} \mathrm{N}\right)$ hasta el norte de Jalisco $\left(21^{\circ} 00^{\prime} \mathrm{N}\right)$. A pesar de su gran importancia ambiental y económica, es todavía deficientemente conocida. Se presenta una sinopsis de los tipos de vegetación, con datos sobre la superficie que ocupan las comunidades reconocidas, intervalos de elevación y climas donde se localizan, así como un mapa. En la zona confluyen tres regiones, albergando ecosistemas templados y semifríos (región Madrense), semiáridos (MadrenseXerófila) y cálido-secos (Tropical), respectivamente. La región Madrense, en el macizo de la sierra, incluye bosque de pino, bosque mixto de coníferas, bosque de pino-encino, bosque de encino y manchones de bosque mesófilo de montaña, además de comunidades como chaparral (primario y secundario) y vegetación de claros de bosque. La región MadrenseXerófila, en el piedemonte norte y oriental y estribaciones al oriente de la sierra, presenta bosque bajo abierto (de encino o de pino-encino), matorral perennifolio y zonas de ecotonía hacia pastizal y matorral xerófilo, además de ecotonías con matorral subtropical hacia el sur del Archipiélago Madrense. En la región Tropical, a lo largo de la base occidental de la sierra e ingresando a esta a través de las barrancas y quebradas, predomina bosque tropical caducifolio y matorral subtropical, con pequeñas áreas de bosque tropical subcaducifolio. La alta diversidad de la SMO se ejemplifica con los tres géneros dominantes fisonómicamente en la vegetación: 24 especies de Pinus (46\% del total nacional), 54 de Quercus (34\%) y 7 de Arbutus (100\%).

Palabras clave: ecosistema, Madrense, Sierra Madre Occidental, vegetación. 


\begin{abstract}
The Sierra Madre Occidental (SMO) is the largest mountain range in Mexico, extending along more than $1200 \mathrm{~km}$ from northeastern Sonora $\left(30^{\circ} 35^{\prime} \mathrm{N}\right)$ ca at the USMexico border to northern Jalisco $\left(21^{\circ} 00^{\prime} \mathrm{N}\right)$ on western Mexico. It includes part of the states of Sonora, Chihuahua, Durango, Zacatecas, as well as small areas of Sinaloa, Nayarit, Jalisco, and Aguascalientes. Of major ecological and economical importance, with a high biological and cultural diversity, this cordilleran complex is not yet well known. For this area, information about the different vegetation types, their elevational ranges, and the climates influencing them, is presented, as is a map showing the geographical distribution of the vegetation types. The area encompasses a confluence of Madrean, Xerophytic Madrean, and Tropical ecosystems. The Madrean region, with temperate and semi-cold climates, includes five vegetation types: pine forest, mixed-conifer forest, pine-oak forest, oak forest and temperate mesophytic forest, as well as communities of primary and secondary chaparral and montane meadow vegetation. The Xerophytic Madrean region, at foothills and eastern branches of the cordillera, has temperate or semi-cold dry climates and a vegetation of oak or pine-oak woodland and evergreen Juniper scrub, with transitions toward the grassland and xerophytic scrub areas of the Mexican high plateau or even to the subtropical scrub at the southern area of the Madrean Archipelago subregion. The Tropical region, entering the SMO through the deep canyons on the western flanks, has warm, semi-warm, and drywarm climates and a prevalence of tropical deciduous forest and subtropical scrub, with small areas of tropical semideciduous forest. The high species richness of this range can be exemplified with the three physiognomically dominant genera: 24 species of Pinus (46\% of the Mexican total), 54 species of Quercus (34\%), and 7 species of Arbutus (100\%).
\end{abstract}

Key words: ecosystem, Madrean, Sierra Madre Occidental, vegetation.

\title{
INTRODUCCIÓN
}

La Sierra Madre Occidental (SMO) es el complejo montañoso más largo y continuo de México, extendiéndose casi desde la frontera con Estados Unidos hasta el norte de Jalisco. Tiene un gran valor económico y ambiental por captar la mayor parte del agua que abastece los mantos freáticos e irriga a amplias zonas en el noroeste de México (González-Elizondo, 1997; Descroix et al., 2004), así como por abastecer de agua y sedimentos los manglares de Marismas Nacionales, de acuerdo con la World Wildlife Foundation (Anónimo, 2011), y por su alta diversidad de es- 
pecies y alta proporción de endemismos. Es un importante corredor biológico tanto para especies boreales como para elementos tropicales de montaña, destacando en el primer caso las plantas leñosas y en el segundo las herbáceas (Rzedowski, 1978; Bye, 1995; Felger et al., 1997) al estar ligada a la planicie de Colorado y a las Montañas Rocosas a través de sierras aisladas (Islas Serranas) y conectada al sur con la Faja Volcánica Transversal. La SMO establece además los límites occidentales de distribución de muchas especies del Desierto Chihuahuense y del Altiplano seco en general, al actuar como barrera entre esa provincia y las comunidades de la planicie costera occidental. Adicionalmente, alberga una importante diversidad biocultural (Bye, 1995; Nabhan, 2005) e incluye a 32 de las 152 Regiones Terrestres Prioritarias (RTPs) de México definidas por la Comisión Nacional para el conocimiento y Uso de la Biodiversidad (CONABIO) (Arriaga et al., 2000). Las RTPs que se localizan de manera total o parcial en la SMO se enlistan en el Apéndice 1.

Los bosques de pino-encino albergan la más alta diversidad florística en México (Rzedowski, 1978) y la Sierra Madre Occidental es particularmente rica por tener la mayor superficie con bosques templados en el país, así como por la confluencia en su territorio de floras de diversos orígenes y por su gran variedad de hábitats. En esta región se presenta además la mayor diversidad de asociaciones de pinos, encinos y madroños a nivel mundial. Dos áreas de la SMO han sido reconocidas como megacentros de diversidad por la Unión Internacional para la Conservación de la Naturaleza (IUCN): el norte de la Sierra Madre (Felger et al., 1997) y la cuenca alta del Río Mezquital (González-Elizondo, 1997). Martin et al. (1998) registran poco más de 2800 especies de plantas para la cuenca del Río Mayo, en el declive occidental de la sierra, y Vázquez-García et al. (2004) reportan 2081 especies para el área huichola, en el extremo sur de la SMO. Estimaciones preliminares de la diversidad del noreste de Sonora, incluyendo el Archipiélago Madrense (Van Devender et al., 2012a) consideran cerca de 2880 taxa de plantas, y únicamente para el municipio de Yécora y sus alrededores se han descrito o se encuentran en proceso de descripción 52 especies de plantas (Van Devender, com. pers.). La flora de la región de Yécora fue estudiada por Van Devender y Reina-Guerrero en 36 viajes entre 1995 y 2008, registrando 1776 taxa en 3,300 km² (Van Devender et al., 2012a), siendo esta una flora casi 30\% más diversa que la de las Huachuca Mountains del sureste de Arizona (Reina-G. y Van Devender, 2005). Un ejemplo con fauna revela que la riqueza de especies de murciélagos de la Sierra Madre Occidental del noroeste de Durango, incluyendo comunidades templadas y tropicales, es comparable a la de las selvas altas húmedas mexicanas, resultado de tener una gran diversidad de hábitats en áreas relativamente pequeñas (Torres-Morales et al., 2010). 
La SMO como provincia florística ha sido considerada por Rzedowski (1978, 1991, 1996) y Rzedowski y Reyna-Trujillo (1990) en la región Mesoamericana de Montaña, zona transicional entre los reinos Holártico y Neotropical, ya que aunque la flora leñosa de los bosques templados de México presenta afinidad boreal, en el componente herbáceo existe también un buen contingente de afinidades tropicales así como de elementos autóctonos. El mismo esquema fue planteado por Halffter (1976) con base en la distribución de insectos (Zona de Transición Mexicana), y reconocido con modificaciones por Morrone et al. (2002); Morrone (2005) y Espinosa et al. (2008).

Entre las zonas montañosas de México, la SMO es la que posee la mayor influencia neártica (Escalante et al., 2005). Muchos taxa pertenecientes al elemento Madroterciario se han descrito para la SMO incluyendo, en los últimos 10 años, un género (Megacorax, González-Elizondo et al., 2002) y varias docenas de nuevas especies y taxa infraespecíficos (Carrillo-Reyes et al. (2003); Nixon y Poole (2003); Estrada et al. (2004); Finot et al. (2004); Adams et al. (2006); Peterson et al. (2006); López-Ferrari y Espejo-Serna (2007); Spellenberg (2007); Carrillo-Reyes (2008); Mayfield y Steinmann (2010); Saarela et al. (2010); Ramírez-Noya et al. (2011); González-Elizondo et al. (2012a); entre otros), lo que revela el gran interés científico de la región.

Entre las diversas contribuciones al conocimiento de la flora y la vegetación de porciones de la SMO, están las de Lumholtz (1902); Gentry (1942); LeSueur (1945); White (1948); Maysilles (1959); Gordon (1968); Búrquez et al. (1992); González-Elizondo y González-Elizondo (1992a, 1992b); González-Elizondo et al. (1993); Laferrière (1994); Casas et al. (1995); DeBano et al. (1995); Felger y Wilson (1995); Fisher et al. (1995); Spellenberg y Bacon (1996); Spellenberg et al. (1996, 1998); Felger et al. (1997, 2001); Estrada-C. et al. (1997); Fulé y Covington (1997); Martin et al. (1998); Búrquez (1998); Reina-G. et al. (1999); Lebgue Keleng (2002, 2005); Enríquez et al. (2003); Estrada-Castillón et al. (2003); García Arévalo y GonzálezElizondo (2003); García Arévalo et al. (2004); Van Devender et al. (2003, 2005); Vázquez-García et al. (2004); González-Elizondo et al. (2005, 2007, 2009a, 2011); Reina-G. y Van Devender (2005); Herrera-Arrieta y Peterson (2007); García Arévalo (2008); Mathiasen et al. (2008); Herrera-Arrieta et al. (2009); Aragón-Piña et al. (2010); Cortés Montaño (2011) y Fulé et al. (2011, 2012). Aunque enfocadas a la región limítrofe entre México y los Estados Unidos, diversas contribuciones en el trabajo de Webster y Bahre (2001) contienen considerable información sobre la vegetación de la SMO. Sin embargo, debido a la extensión y complejidad de la zona, la información disponible sigue siendo insuficiente. Ejemplo de lo anterior es el re- 
ciente descubrimiento de una población de Pinus maximartinezii Rzed. (GonzálezElizondo et al., 2011), a casi cinco décadas de que la especie se conociera solamente del sur de Zacatecas. Por otra parte, los datos que existen actualmente sobre la composición y tipos de vegetación de la región y las estadísticas acerca de la cobertura y uso del suelo varían mucho dependiendo de la escala y la fuente de la que provienen (Anónimo, 1973; Rzedowski, 1978; Brown et al., 1998; Anónimo, 2002; Koleff et al., 2004; González Elizondo et al., 2007).

Datos paleoclimáticos y de cambios en la vegetación para algunas áreas de la SMO han sido registrados por Ortega-Ramírez et al. (1998), Ortega-Rosas et al. (2008a,b) y Metcalfe et al. (2000, 2002); por ejemplo, Ortega-Rosas et al. (2008a) reportan que para Yécora, Sonora, el clima era más fresco y húmedo hace alrededor de 1000 años. En cuanto a las proyecciones de cambio de la vegetación con base en modelos de cambio climático, la Sierra Madre Occidental es considerada por Villers-Ruiz y Trejo-Vázquez (1998) entre las zonas con bosque templado que son más sensibles al cambio; y en general, los bosques de coníferas y encinos son el tipo de vegetación que más superficie perderá (Arriaga y Gómez, 2004; Villers-Ruiz y Trejo-Vázquez, 2004).

En este trabajo se presenta una caracterización de los tipos de vegetación de la Sierra Madre Occidental. La clasificación de las comunidades vegetales ajustada a las características de la región constituye un marco de referencia para conocer, interpretar y valorar a los ecosistemas naturales y puede ser una herramienta de primera mano para la elaboración de diagnósticos, inventarios y descripción de comunidades, así como para la planeación del uso, manejo y conservación de los recursos (González Elizondo et al., 2007).

\section{MATERIALES Y MÉTODOS}

La clasificación de las comunidades vegetales de la Sierra Madre Occidental se basa en muestreos llevados a cabo entre octubre de 2007 y noviembre de 2011 en los que se georreferenciaron 140 sitios en los que se registró el tipo de vegetación, las especies dominantes fisonómicamente y variables del medio físico (situación geográfica, elevación, topografía y profundidad del suelo). Lo anterior se complementa con datos recopilados mediante reconocimiento visual en la SMO a lo largo de más de dos décadas. Se llevaron a cabo colectas botánicas y toma de imágenes fotográficas en los sitios muestreados, y posteriormente o in situ la identificación taxonómica de las muestras. Para la elaboración del mapa de vegetación se delimitaron unidades car- 
tográficas con base en los datos vectoriales de uso del suelo y vegetación Serie III del Instituto Nacional de Estadística y Geografía (INEGI) (Anónimo, 2002), verificando con la información de campo así como con datos de literatura para zonas que no fueron visitadas. Los datos taxonómicos y geográficos fueron capturados en una base de datos MS Access de la cual se recuperó la información para verificar o ajustar polígonos con lo que se generó el mapa usando ArcGis 9.3. Mapas digitalizados de climas y de elevaciones se intersectaron con el de vegetación para calcular las proporciones de las diferentes categorías de esas variables ambientales con las de vegetación.

Descripción del área de estudio

La Sierra Madre Occidental es el más largo y continuo de los sistemas montañosos de México: una cadena de cerca de $1160 \mathrm{~km}$ de longitud y áreas con más de $200 \mathrm{~km}$ de ancho, con las siguientes coordenadas extremas: $30^{\circ} 35^{\prime}-21^{\circ} 00^{\prime} \mathrm{N},-109^{\circ} 10^{\prime}-$ $102^{\circ} 25^{\prime}$ W. Más de cincuenta montañas aisladas en el noreste de Sonora, sureste de Arizona y extremo suroeste de Nuevo México constituyen Islas Serranas a las que se conoce como Archipiélago Madrense (Madrean Sky Islands), las cuales representan un puente entre la SMO y las Montañas Rocosas y la Planicie de Colorado.

El límite oriental de la sierra es, hacia su latitud central, la cota altitudinal de $1800 \mathrm{~m}$, donde inicia la transición hacia el Altiplano, mientras que el límite al occidente es muy bajo $(300 \mathrm{~m}$ ) debido al fuerte declive hacia el Pacífico; hacia el norte se consideró un promedio de $1400 \mathrm{~m}$ (Fig. 1). Las ramificaciones y serranías aisladas de las SMO hacia el noreste encierran amplios valles intermontanos, como el de Babícora en Chihuahua. La superficie total así considerada es cercana a un cuarto de millón de kilómetros cuadrados $\left(251,648 \mathrm{~km}^{2}\right)$, cerca de 1/8 del territorio nacional.

Como provincia morfotectónica, la SMO es una de las provincias ígneas silícicas más grandes del mundo y la más grande del Cenozoico. Su cubierta ignimbrítica se estima en la actualidad en $\sim 300,000 \mathrm{~km}^{2}$ (McDowell y Keizer, 1977, citados por Ferrari et al., 2005) o unos 289,000 km² (Ferrusquía-Villafranca, 1993). La estratigrafía de la SMO consta de cinco conjuntos ígneos principales, el más antiguo formado por rocas del Cretácico superior-Paleoceno y el más reciente derivado de diferentes episodios del Mioceno tardío, Plioceno y Cuaternario (Ferrari et al., 2005). El levantamiento de la sierra ocurrió en el Oligoceno tardío y el Mioceno medio (hace 25-15 millones de años) y sus capas más recientes, del Plioceno y el Pleistoceno ( $<5$ millones de años) están constituidas por ignimbritas (principalmente riolitas y tobas) y por basaltos alcalinos.

El macizo de la sierra presenta una orientación NNO-SSE, desde el noreste de Sonora al norte de Jalisco, donde se une con el Eje Neovolcánico. La sierra tie- 
ne la forma de una meseta ligeramente inclinada al oriente que ha sido dislocada por fallas y cortada por corrientes que descienden tanto al Golfo de California y el Océano Pacífico, como al Altiplano Mexicano (Morán Zenteno, 2007). Su flanco occidental es sumamente escarpado, con numerosas y profundas hondonadas (llamadas "barrancas" en Sonora y Chihuahua, "quebradas" en Durango y Sinaloa y "cañones" o "barrancas" en Zacatecas y norte de Jalisco), en algunos sitios de más de $1800 \mathrm{~m}$ de profundidad. Entre estas destacan las de Urique, El Cobre, Sinforosa y Candameña en Chihuahua; Humaya, Tamazula, San Lorenzo, Piaxtla, Presidio y Baluarte (Durango-Sinaloa); Acaponeta y Mezquital (Durango-Nayarit); y Jesús María o Santiago, Bolaños, Huaynamota y Juchipila (Durango-Zacatecas-JaliscoNayarit). La rugosidad del relieve alcanza su mayor expresión en la quebrada del río Mezquital, la cual atraviesa por completo la sierra entre el norte de Nayarit y el sur de Durango, siendo esta la única corriente en la SMO que nace del lado oriental de la sierra y desemboca hacia el Pacífico.

En contraste, las laderas de la vertiente oriental de la SMO son mucho menos abruptas por la gradual diferencia de niveles en su transición hacia el Altiplano (González Elizondo et al., 2007). La sierra tiene una elevación media de $2500 \mathrm{~m}$ pero alcanza los $3340 \mathrm{~m}$. Las principales cimas son el Cerro Gordo (3347 m), Barajas (3310 m), Mohinora (3307 m), Huehuento (3262 m) y el cerro de Las Antenas en la Sierra El Epazote (3224 m), todos en Durango a excepción del Mohinora que se localiza al suroeste de Chihuahua.

Los ríos más importantes de la SMO que drenan hacia el Pacífico son el Yaqui, Mayo, Fuerte, Humaya, Presidio, Baluarte, San Pedro-Mezquital y Acaponeta, así como el río Huazamota, que hacia el sur forma parte del río Grande de Santiago, del sistema Lerma-Santiago. Hacia la cuenca del Golfo de México, varias corrientes son afluentes del río Conchos, uno de los principales tributarios del Bravo, mientras que entre los que tienen cuencas endorreicas destacan el Casas Grandes, el Santa María y el Carmen, que desembocan al norte de la sierra en las lagunas de Guzmán, Santa María y Patos, respectivamente, así como el Nazas y el Aguanaval, los dos ríos más importantes de la vertiente interior del país. La SMO funciona como sombra orográfica para la humedad del Pacífico, que llega solo parcialmente al Altiplano y al Desierto Chihuahuense; es además una barrera entre los desiertos Sonorense y Chihuahuense y aporta el agua con la que estos se sustentan.

\section{Climas}

Los principales climas de la SMO se presentan en el Cuadro 1. Las claves corresponden al sistema de Köppen modificado por García (1998). 
Cuadro 1. Tipos de climas de la Sierra Madre Occidental y superficie que ocupan. Adaptado de Instituto Nacional de Estadística y Geografía (Anónimo, 2003). Conjunto de datos vectoriales de la carta de climas escala 1:1 000000 . Los subíndices ${ }_{0,1,} \mathrm{y}_{2}$ se refieren al cociente de la precipitación media anual/temperatura media anual $(\mathrm{P} / \mathrm{T}) .<43=\mathrm{w}_{0}$, entre 43 y $55=w_{1}$ y $>55=w_{2}$.

\begin{tabular}{|c|c|c|c|}
\hline Clave & Descripción & Área $\left(\mathrm{km}^{2}\right)$ & $\%$ \\
\hline $\mathrm{Aw}_{0}$ & Cálido subhúmedo, lluvias en verano. $\mathrm{P} / \mathrm{T}<43$ & $8,631.74$ & 3.426 \\
\hline $\mathrm{Aw}_{1}$ & Cálido subhúmedo, lluvias en verano. P/T 43-55 & $5,751.66$ & 2.283 \\
\hline $\mathrm{Aw}_{2}$ & Cálido subhúmedo, lluvias en verano. P/T > 55 & $3,065.92$ & 1.217 \\
\hline $\mathrm{A}(\mathrm{C}) \mathrm{w}_{2}(\mathrm{w})$ & $\begin{array}{l}\text { Semicálido subhúmedo, el más fresco de los } \\
\text { semicálidos; lluvias en verano. } \mathrm{P} / \mathrm{T}>55\end{array}$ & 273.99 & 0.109 \\
\hline$(\mathrm{A}) \mathrm{C}\left(\mathrm{w}_{0}\right)$ & Semicálido subhúmedo, lluvias en verano. $\mathrm{P} / \mathrm{T}<43$ & $18,328.75$ & 7.276 \\
\hline$(\mathrm{A}) \mathrm{C}\left(\mathrm{w}_{1}\right)$ & $\begin{array}{l}\text { Semicálido subhúmedo, lluvias en verano. T del mes } \\
\text { más frío }<18^{\circ} \mathrm{C}, \mathrm{T} \text { media anual } 18-22^{\circ} \mathrm{C} . \mathrm{P} / \mathrm{T} 43-55\end{array}$ & $11,650.31$ & 4.625 \\
\hline$(\mathrm{A}) \mathrm{C}\left(\mathrm{w}_{2}\right)$ & Semicálido subhúmedo, lluvias en verano. P/T > 55 & $5,972.09$ & 2.371 \\
\hline $\operatorname{Otros}(\mathrm{A}) \mathrm{C}$ & Semicálidos subhúmedos & $1,387.14$ & 0.551 \\
\hline $\mathrm{BS}_{1} \mathrm{hw}$ & Semiseco semicálido. P/T > 22.9 & $5,729.79$ & 2.276 \\
\hline $\mathrm{BS}_{1} \mathrm{hw}\left(\mathrm{x}^{\prime}\right)$ & $\begin{array}{l}\text { Semiseco semicálido, porcentaje de lluvia invernal } \\
\text { mayor que } 10.2 \% \text { del anual. } \mathrm{P} / \mathrm{T}>22.9\end{array}$ & $6,320.53$ & 2.509 \\
\hline $\mathrm{BS}_{1}\left(\mathrm{~h}^{\prime}\right) \mathrm{w}$ & $\begin{array}{l}\text { Semiseco, cálido, temperatura media anual mayor de } \\
22{ }^{\circ} \mathrm{C} \text {, lluvias en verano. } \mathrm{P} / \mathrm{T}>22.9\end{array}$ & $3,274.78$ & 1.3 \\
\hline $\mathrm{BS}_{1} \mathrm{kw}$ & $\begin{array}{l}\text { Semiseco templado con verano cálido, temperatura del } \\
\text { mes más cálido }>18^{\circ} \mathrm{C} . \mathrm{P} / \mathrm{T}>22.9\end{array}$ & $38,700.08$ & 15.362 \\
\hline $\mathrm{BS}_{1} \mathrm{kw}\left(\mathrm{x}^{\prime}\right)$ & $\begin{array}{l}\text { Semiseco templado con verano cálido; temperatura del } \\
\text { mes más cálido }>18^{\circ} \mathrm{C} \text {; porcentaje de lluvia invernal } \\
\text { mayor que } 10.2 \% \text { del anual. } \mathrm{P} / \mathrm{T}>22.9\end{array}$ & $13,134.72$ & 5.214 \\
\hline Otros BS & Secos y semisecos & $2,033.73$ & 0.808 \\
\hline $\mathrm{C}\left(\mathrm{w}_{0}\right)$ & $\begin{array}{l}\text { Templado subhúmedo. T media anual } 12-18{ }^{\circ} \mathrm{C} \text {, T del } \\
\text { mes más frío entre }-3^{\circ} \mathrm{C} \text { y } 18{ }^{\circ} \mathrm{C} \text {. } \mathrm{P} / \mathrm{T}<43\end{array}$ & $23,459.04$ & 9.312 \\
\hline$C\left(\mathrm{w}_{0}\right)\left(\mathrm{x}^{\prime}\right)$ & $\begin{array}{l}\text { Templado subhúmedo con lluvias uniformemente } \\
\text { repartidas en el año. T media anual } 12-18{ }^{\circ} \mathrm{C} \text {, T del } \\
\text { mes más frío entre }-3^{\circ} \mathrm{C} \text { y } 18^{\circ} \mathrm{C} \text {, T del mes más } \\
\text { caliente }<22{ }^{\circ} \mathrm{C} \text {; precipitación anual } 200-1800 \mathrm{~mm} \\
\text { y precipitación en el mes más seco } 0-40 \mathrm{~mm} \text {. } \mathrm{P} / \mathrm{T} \\
<43\end{array}$ & $5,414.17$ & 2.149 \\
\hline $\mathrm{C}\left(\mathrm{w}_{1}\right)$ & $\begin{array}{l}\text { Templado subhúmedo con lluvias en verano. T media } \\
\text { anual } 12-18^{\circ} \mathrm{C} \text {; precipitación anual } 200-1800 \mathrm{~mm} \text {. } \\
\text { P/T } 43-55\end{array}$ & $22,089.06$ & 8.768 \\
\hline
\end{tabular}


Cuadro 1. Continuación.

\begin{tabular}{|c|c|c|c|}
\hline Clave clima & Descripción & Área $\left(\mathrm{km}^{2}\right)$ & $\%$ \\
\hline $\mathrm{C}\left(\mathrm{w}_{1}\right)\left(\mathrm{x}^{\prime}\right)$ & $\begin{array}{l}\text { Templado subhúmedo con lluvias uniformemente } \\
\text { repartidas en el año. T media anual } 12-18{ }^{\circ} \mathrm{C} \text {, T } \\
\text { del mes más frío }-3-18{ }^{\circ} \mathrm{C} \text {, T del mes más caliente } \\
\text { bajo }<22{ }^{\circ} \mathrm{C} \text {; precipitación anual } 200-1800 \mathrm{~mm} \text { y } \\
\text { precipitación en el mes más seco } 0-40 \mathrm{~mm} \text {. P/T } 43-55\end{array}$ & $8,070.70$ & 3.204 \\
\hline $\mathrm{C}\left(\mathrm{w}_{2}\right)$ & $\begin{array}{l}\text { Templado subhúmedo, lluvias en verano, T media } \\
\text { anual } 12-18^{\circ} \mathrm{C} . \mathrm{P} / \mathrm{T}>55\end{array}$ & $14,545.82$ & 5.774 \\
\hline $\mathrm{C}\left(\mathrm{w}_{2}\right)\left(\mathrm{x}^{\prime}\right)$ & $\begin{array}{l}\text { Templado subhúmedo, } \mathrm{T} \text { media anual } 12-18^{\circ} \mathrm{C} \text {, T } \\
\text { del mes más frío entre }-3^{\circ} \mathrm{C} \text { y } 18^{\circ} \mathrm{C} \text { y temperatura } \\
\text { del mes más caliente bajo } 22^{\circ} \mathrm{C} \text {; precipitación anual } \\
200-1800 \text { mm y precipitación en el mes más seco de } 0 \\
\text { a } 40 \mathrm{~mm} \text {; lluvias en invierno mayores al } 10.2 \% \text { anual. } \\
\mathrm{P} / \mathrm{T}>55\end{array}$ & $11,692.36$ & 4.641 \\
\hline $\mathrm{C}(\mathrm{E})\left(\mathrm{w}_{2}\right)$ & Semifrío subhúmedo con lluvias en verano. $\mathrm{P} / \mathrm{T}>55$ & $18,376.37$ & 7.294 \\
\hline $\begin{array}{l}\mathrm{C}(\mathrm{E})\left(\mathrm{w}_{2}\right) \\
\left(\mathrm{x}^{\prime}\right)\end{array}$ & $\begin{array}{l}\text { Semifrío subhúmedo con lluvias uniformemente } \\
\text { repartidas. } \mathrm{P} / \mathrm{T}>55\end{array}$ & $14,532.82$ & 5.769 \\
\hline Otros C(E) & Semifríos & $9,212.59$ & 3.657 \\
\hline
\end{tabular}

TOTAL $\quad 251,648.15 \quad 100.000$

A través de una sección transversal de la sierra, de oriente a poniente, se presentan cuatro zonas climáticas generales: a) climas secos y semisecos (tipo BS), en el piedemonte y estribaciones al oriente, norte y noroeste; b) climas templados y semifríos ( $\mathrm{C}$ y $\mathrm{C}(\mathrm{E})$, respectivamente) en la parte alta y parte media, semisecos hacia la vertiente oriental y subhúmedos hacia la occidental; c) semicálidos $(\mathrm{A}(\mathrm{C})$ y $(A) C$ ) en la vertiente occidental; y d) cálidos (A) en las partes bajas y cañadas de la SMO. La temporada de lluvias es en verano (w) y en general los climas tienen una marcada estacionalidad anual, a excepción de los que llevan la extensión (x’), la cual indica lluvias uniformemente repartidas durante el año (proporción alta de lluvias en invierno). Los climas A tienen temperatura media del mes más frío superior a $18^{\circ} \mathrm{C}$, y no presentan heladas.

En la parte norte de la SMO así como en las porciones más altas de la zona media y oriental el clima es muy extremoso, con marcada oscilación diaria y anual de temperaturas y con heladas muy severas, tanto por su carácter continental como 
por la influencia de vientos boreales ("nortes"), los cuales afectan también a la vertiente oriental de la sierra. En el Archipiélago Madrense las temperaturas mínimas descienden a extremos similares a los que ocurren en las Rocallosas y en la Planicie de Colorado. Por otra parte, los climas de la vertiente occidental de la sierra son más húmedos y menos extremosos.

\section{RESULTADOS Y DISCUSIÓN}

Se describen y cartografían nueve tipos de vegetación y diversas comunidades vegetales (Fig. 2), para los cuales se registra la superficie que ocupan y los intervalos de elevación donde se encuentran en la SMO (Cuadro 2), climas donde se localizan y algunas de las principales asociaciones que los representan. La lista de especies arbóreas y arbustivas de los principales componentes fisonómicos de la vegetación madrense de la SMO (pinos y otras gimnospermas, encinos y madroños), se presentan en el Apéndice 2. Se registran 24 especies de pinos (46\% del total nacional), 54 de encinos (34\%) y 7 de madroños (100\%), lo que corrobora la alta riqueza de especies en la región.

La clasificación de la vegetación es adaptada de la de Rzedowski (1978), un sistema entre cuyas ventajas están la de emplear categorías básicas y excluyentes, lo que permite una relativa facilidad de cartografiado, facilita la subcategorización y también la comparación con otros sistemas usados para el resto del mundo (González Elizondo et al., 2007). Dicho sistema combina criterios fisonómicos, florísticos y ecológicos similares a los del propuestos por la UNESCO (Anónimo, 1973) para clasificar la vegetación del planeta y ha sido adoptado con algunas modificaciones por el INEGI (Anónimo, 2005) y por Challenger y Soberón (2008) en la descripción de los ecosistemas terrestres del país para la obra Capital Natural de México. En el presente trabajo las categorías usadas se refieren a la cubierta vegetal actual. Dado que la clasificación propuesta por Rzedowski está dirigida a la vegetación potencial y es a una escala de país, los enfoques regionales como el presente necesariamente requieren de una adaptación y adiciones de categorías.

Los tipos de vegetación y comunidades reconocidos se agrupan en tres grandes apartados: Madrense, Madrense-Xerófila y Tropical, correspondientes a las afinidades de los componentes de la vegetación que prevalece en las tres ecorregiones terrestres de México de nivel II que confluyen en el área: "Sierras templadas, Sierra Madre Occidental", "Elevaciones semiáridas, piedemonte de la Sierra Madre Occidental" y "Bosques tropicales secos, planicie costera, lomeríos y cañones del 
Cuadro 2. Tipos de vegetación y uso del suelo en la Sierra Madre Occidental, con la superficie que ocupan e intervalos altitudinales donde se presentan.

\begin{tabular}{|c|c|c|c|}
\hline Vegetación o uso del suelo & Superficie $\mathrm{km}^{2}$ & $\%$ & Elevación m s.n.m. \\
\hline \multicolumn{4}{|l|}{ REGIÓN MADRENSE } \\
\hline Bosque de pino & $30,152.53$ & 11.982 & $(1000-) 1600-3320$ \\
\hline Bosque de pino-encino & $76,265.48$ & 30.306 & $(600-) 1250-3200$ \\
\hline Bosque de encino & $34,616.64$ & 13.756 & $(340-) 1100-2900$ \\
\hline Bosque mixto de coníferas & 689.27 & 0.274 & $1900-3300$ \\
\hline Bosque mesófilo de montaña & 347.05 & 0.138 & $(750-) 1600-2350$ \\
\hline Chaparral secundario & $2,049.41$ & 0.814 & $2300-3000$ \\
\hline Claros en bosque & 930.76 & 0.370 & $2300-3340$ \\
\hline \multicolumn{4}{|l|}{ MADRENSE-XERÓFILA } \\
\hline Bosque bajo abierto & $32,062.11$ & 12.741 & $1450-2500(-2800)$ \\
\hline Matorral perennifolio & 364.38 & 0.145 & $1500-2300$ \\
\hline Chaparral & 616.97 & 0.245 & $1900-2500$ \\
\hline \multicolumn{4}{|l|}{ REGIÓN XERÓFILA } \\
\hline Pastizal & $10,266.65$ & 4.080 & $1200-2200$ \\
\hline Matorral xerófilo & 969.24 & 0.385 & $1000-2250$ \\
\hline Bosque xerófilo espinoso & 88.13 & 0.035 & $1800-1900$ \\
\hline Pastizal halófilo & 83.80 & 0.033 & $2000-2200$ \\
\hline \multicolumn{4}{|l|}{ REGIÓN TROPICAL } \\
\hline Bosque tropical caducifolio & $17,827.60$ & 7.084 & $200-2000(-2160)$ \\
\hline Bosque tropical subcaducifolio & $3,950.88$ & 1.570 & $350-1200$ \\
\hline Matorral subtropical & $9,999.42$ & 3.974 & $(300-) 500-2050$ \\
\hline \multicolumn{4}{|l|}{ OTROS } \\
\hline Cuerpo de agua & 512.58 & 0.204 & $300-2800$ \\
\hline Bosque de galería & 84.19 & 0.033 & $300-2900$ \\
\hline Pastizal inducido & $11,485.94$ & 4.564 & $300-3100$ \\
\hline Agricultura & $17,928.85$ & 7.124 & $300-2900$ \\
\hline Sin vegetación & 77.49 & 0.031 & $2100-2900$ \\
\hline Asentamiento humano & 278.37 & 0.111 & $300-2800$ \\
\hline Total & $251,648.15$ & $100.00 \%$ & \\
\hline
\end{tabular}

Occidente", de acuerdo a la clasificación de la Comisión para la Cooperación Ambiental de América del Norte (CCA) (Anómimo, 1997). Una propuesta preliminar de subregionalización se presenta por González-Elizondo et al. (2012b). 
La región Madrense (Brown et al., 1995, 1998; Felger et al., 1997) cubre el macizo de la SMO por encima de los $2200 \mathrm{~m}$ en la porción sur de la sierra y desde los 1550 $m$ en la porción norte, mientras que las zonas Semiárida y Tropical se encuentran en las partes bajas y en las zonas circundantes a la SMO. El nombre de región Madrense (o provincia biogeográfica Madro-Cordillerana) ha sido aplicado en sentido muy amplio por diversos autores. En este trabajo se sigue el concepto de Brown (1982, citado en Brown et al., 1998) de "comunidades de elevaciones medias y altas de la Sierra Madre Occidental, Sierra Madre Oriental y sus estribaciones", aplicado a la Sierra Madre Occidental. Las comunidades de las partes bajas y semiáridas hacia el norte y oriente de la SMO, en ecotonía con las comunidades del altiplano y correspondientes a la ecorregión Altiplanicies Semiáridas de INEGI-CONABIO-INE (Anónimo, 2007), se incluyen aquí en la región Madrense-Xerófila, para realzar la afiliación madrense de sus elementos (bosques bajos abiertos de pino y encino, matorrales de táscate y chaparrales). Las comunidades xerófilas del altiplano (pastizales, matorrales) son mencionadas únicamente por presentar ecotonías con la vegetación Madrense-Xerófila.

La mayor parte de las comunidades vegetales de la SMO son de tipo zonal, determinadas por el clima. A escalas más finas, existen algunas cuya existencia depende de factores geomorfológicos o edáficos, entre las que destacan las ciénegas de bajíos inundables y las cimas de altas montañas, así como una parte de los bosques de Pinus lumholtzii, los que se desarrollan sobre afloramientos de roca blanquecina muy intemperizada, denominados "calichales" aunque su $\mathrm{pH}$ es ácido. Ciertos suelos rojizos muy ácidos ( $\mathrm{pH}$ hasta 4.0) derivados de roca volcánica hidrotérmicamente alterada (gossans, Goldberg, 1982) presentan encinares bajos o bosques de pino-encino rodeados de bosque tropical caducifolio sobre suelos no alterados, como registran Van Devender et al. (2005) para Sonora, entre 820 y 920 m s.n.m. Situaciones similares ocurren en partes medias y bajas del declive occidental de la sierra en Durango y Zacatecas.

El término asociación se refiere a comunidades vegetales con dos o más especies dominantes fisonómicamente, mientras que consociación aplica para las comunidades con una sola especie dominante. La superficie que ocupa la vegetación y usos del suelo y los intervalos altitudinales donde se desarrollan se presentan en el Cuadro 2.

\section{REGIÓN MADRENSE}

Se ubica en el macizo de la sierra y serranías al noroeste, desde los $1550 \mathrm{~m}$ en la porción norte de la sierra y por encima de los $2200 \mathrm{~m}$ en la parte sur, aunque 
algunas especies termófilas de pino y encino bajan a menores elevaciones. Los climas son templados y semifríos en la parte alta y la vertiente oriental de la sierra y templado-semicálidos y subhúmedos en la vertiente occidental. Incluye una zona en la que el clima es menos extremo, templado subhúmedo y las especies que la componen presentan distribución hacia el sur. Esta zona se localiza en la vertiente occidental de la sierra, entre los 1100 y $2300 \mathrm{~m}$ en una franja entre la zona Madrense s.s. y las comunidades de bosque tropical y en ecotonía con estas, a la que se denomina aquí Madrense Tropical. Aunque sus tipos de vegetación son los mismos que los de la región Madrense en partes más elevadas (bosques de pino, pino-encino y mixtos de coníferas), las especies que los componen son diferentes (Ver Apéndice 2).

\section{1. Bosque de pino}

Cubre $12 \%$ de la superficie de la SMO, entre los (1000-)1600 y los $3320 \mathrm{~m}$ s.n.m., con la principal zona por encima de los $2300 \mathrm{~m}$, sobre roca ígnea. Se presenta en diversas variantes y diferentes condiciones ambientales, en climas templados y templado-semifríos, desde semisecos a húmedos. El elemento común en estas comunidades es la dominancia fisonómica de especies de Pinus ( $80 \%$ o más). La estructura de tales bosques varía de simple, con una sola especie dominante, a veces con solo un estrato arbóreo, uno herbáceo y otro rasante, hasta la estructura compleja de bosques de sitios con clima subhúmedo con varias especies de pino y a veces de otros géneros, dos estratos arbóreos además de arbustivo, herbáceo y rasante, con hemiparásitas $\mathrm{y}$ epífitas. Tanto en los bosques de pino como en los de pino-encino predominan en el estrato herbáceo especies de las familias Asteraceae y Poaceae. Las poáceas dominantes son perennes, de talla mediana, generalmente amacolladas. El género Muhlenbergia está particularmente bien representado, así como Schizachyrium, Piptochaetium fimbriatum, Aristida, Bouteloua, Heteropogon y Elyonurus.

Algunas asociaciones o consociaciones de bosque de pino son las siguientes:

Hacia la porción norte de la sierra los pinos dominantes son P. arizonica, con frecuencia formando masas puras hasta los $2700 \mathrm{~m}$ s.n.m o asociado con Pinus engelmanii y $P$. strobiformis, los cuales lo substituyen en sitios con mayor humedad ambiental. En Chihuahua, entre 2200 y 2300 m, hay bosques más o menos densos de Pinus arizonica, $P$. durangensis, $P$. lumholtzii y Pinus sp. Más al sur, en Durango, $P$. arizonica se asocia con $P$. teocote y Arbutus spp. Sobre laderas pedregosas con suelo pobre Pinus teocote puede ser abundante y a veces forma masas puras.

Pinus cooperi es una especie endémica a la SMO, abundante en valles intermontanos. Forma masas puras alrededor de bajíos con suelo profundo y drenaje pobre, entre los 2400 y 2750 m, desde el centro de Chihuahua hasta el sur de Durango y 
noreste de Nayarit (con frecuencia es registrado como P. arizonica). En el estrato arbustivo estos bosques pueden presentar Juniperus deppeana, Arctostaphylos pungens y/o encinilla (Quercus striatula), un arbusto enano indicador de perturbación por fuego. Pinus cooperi a veces se acompaña o es substituido por P. leiophylla (González Elizondo et al., 2007). Pinus leiophylla puede ser monodominante o mezclarse con $P$. cooperi en alrededores de bajíos; hacia las laderas la diversidad de especies leñosas se hace más compleja, combinándose con encinos, principalmente $Q$. sideroxyla.

A mayores elevaciones, hasta los $3320 \mathrm{~m}$, en mesas y cimas de cerros altos (Gordo, Barajas y Mohinora) se presenta una variante identificada tentativamente como Pinus aff. cooperi.

Bosques muy abiertos de Pinus chihuahuana, P. lumholtzii y Juniperus durangensis se conocen de Chihuahua y Durango. En la vertiente oriental, más seca, se presentan bosques abiertos de pino real o pino apache ( $P$. engelmannii), a veces en ecotonía con los bosques bajos abiertos. El pino chino, Pinus chihuahuana, es abundante en laderas secas y rocosas en la periferia de los bosques de $P$. engelmannii o en ecotonías con los bosques bajos abiertos.

Bosques de pino triste (Pinus lumholtzii) son característicos de afloramientos de toba o riolita hidrotérmicamente alterados y muy intemperizados, con suelos muy someros, ácidos. Se desarrollan especialmente sobre collados y laderas con influencia de fuertes corrientes de aire desecante. Son comunidades muy abiertas, donde además del pino triste destacan Quercus spp. (Q. jonesii, Q. radiata, Q. rugosa y/o Q. urbanii), Arbutus bicolor y/o A. madrensis, Juniperus durangensis y/o J. deppea$n a$, Arctostaphylos pungens, a veces otras especies de pino como $P$. teocote y $P$. cf. arizonica. Hacia el sur de la sierra $P$. lumholtzii se asocia también con $P$. chihuahua$n a$. Otras comunidades de $P$. lumholtzii existen sobre laderas suaves con suelos profundos y con abundante hojarasca, por ejemplo en el occidente de Durango y oriente de Sinaloa, entre los 1900 y $2000 \mathrm{~m}$. Estas comunidades son más densas y en ellas se desarrollan también otros pinos y encinos con Arbutus tessellata.

En partes altas de la vertiente occidental de la sierra Pinus durangensis forma masas puras sobre laderas con escasa pendiente y clima relativamente húmedo. En condiciones favorables este árbol llega a alcanzar hasta $42 \mathrm{~m}$ de alto y más de $1 \mathrm{~m}$ de diámetro troncal. Entre los elementos que se asocian están P. arizonica, P. teocote y P. leiophylla.

En cañadas húmedas Pinus strobiformis es el pino más común, principalmente en suelos húmedos y bien drenados.

En la Subregión Madrense Tropical de la vertiente occidental de la SMO se desarrollan bosques de $P$. durangensis. En partes más bajas $(<2400 \mathrm{~m})$ y menos frías hay comunidades muy variables en composición y densidad, en donde son comunes $P$. 
yecorensis, Pinus oocarpa, P. luzmariae, P. devoniana, P. douglasiana, P. lumholtzii, P. herrerae y/o P. maximinoi. Entre 1600 y 2100 m existen comunidades de pino y madroño con Pinus devoniana, P. maximinoi, P. herrerae, P. lumholtzii, P. oocarpa, Arbutus tessellata, A. madrensis y A. xalapensis (González Elizondo et al., 2007). Hacia sus límites inferiores estas comunidades se substituyen por bosques casi puros de $P$. oocarpa.

\section{2. Bosque mixto de coníferas}

Cubre menos de $0.3 \%$ del área en manchones aislados entre los 1900 y 3300 $\mathrm{m}$, particularmente en las partes altas, así como en la vertiente occidental de la sierra, sobre roca ígnea. Los climas van de templados subhúmedos a semifríos húmedos, o menos húmedos en cuyo caso estos bosques se localizan en cañadas y laderas expuestas al norte donde la sombra orográfica protege de los vientos secos y de la insolación y mantiene bajas temperaturas y alta humedad a nivel local.

Están dominados fisonómicamente por coníferas de los géneros Abies, Pseudotsuga y/o Picea, con frecuencia con pinos y encinos. Destacan los oyameles o cahuites (Abies durangensis) y los pinabetes o cahuites (Pseudotsuga menziesii var. glauca y Pinus strobiformis). Usualmente se combinan con encinos y otras angiospermas como Arbutus bicolor, A. madrensis, Alnus y Cornus. En el estrato arbustivo hay Arbutus occidentalis (madroño enano), Ceanothus, Ribes, Rubus, Vaccinium y Pernettya (González Elizondo et al., 2007).

Bosques de Picea chihuahuana se conocen desde Chihuahua al sur de Durango pero están reducidos a pequeñas poblaciones restringidas a cañadas ribereñas. Esta especie es de distribución geográfica muy restringida, relictual, endémica a la Sierra Madre Occidental (Jaramillo-Correa et al., 2006; García Arévalo, 2008). De distribución previa más amplia cuando las condiciones ambientales de mayor humedad y temperaturas relativamente bajas prevalecían en buena parte de México, hace unos 9000 años, casi desapareció del área (Gordon 1968; Wehenkel y Saenz-Romero, 2012). Actualmente se conoce de rodales muy pequeños en cañadas húmedas en Chihuahua y Durango entre 2300 y 2850 m de altitud.

En lugares fríos en Sonora se presentan Abies concolor, A. durangensis y Pseudotsuga menziesii, el primero alcanzando ahí su límite austral de distribución y los otros con distribución amplia en la SMO. Una especie de área mucho más reducida es Abies neodurangensis, conocida solamente de la vertiente occidental de la sierra en Durango a menores elevaciones que $A$. durangensis.

Restringidos a cañadas o laderas con alta humedad ambiental se presentan cipreses: Cupressus (Hesperocyparis) arizonica en el norte del área y C. lusitanica desde el este de Sonora y occidente de Chihuahua hasta Jalisco. 
Entre las angiospermas que forman parte de bosques mixtos destacan los encinos Quercus sideroxyla y Q. rugosa, álamo temblón (Populus tremuloides), fresnos (Fraxinus spp.) y capulín (Prunus serotina). Felger y Johnson (1995) registran para bosques mixtos del extremo norte de la sierra a Quercus gambelii y a Acer grandidentatum y al alamillo Alnus oblongifolia en cañadas ribereñas. Estos mismos autores citan para el noreste de Sonora y noroeste de Chihuahua bosques mixtos de coníferas por encima de los $2130 \mathrm{~m}$, y Martin et al. (1998) los reportan para la parte alta de la cuenca del Río Mayo.

En toda la SMO Pseudotsuga menziesii llega a encontrarse dentro de los bosques de pino o de pino-encino en áreas localizadas, sobre todo en sitios con alta humedad, con exposición al norte o en cañadas con arroyo, de manera que no existe una línea divisoria entre estas comunidades y el bosque mixto de coníferas.

\section{3. Bosque de pino-encino}

Es el tipo de vegetación dominante en la SMO, cubriendo un 30\% de la superficie. Se encuentra principalmente entre los 1250 y los $3200 \mathrm{~m}$ de elevación pero algunas comunidades descienden hasta los $600 \mathrm{~m}$ sobre la vertiente occidental de la Sierra; en la vertiente oriental las más bajas inician a partir de los $2300 \mathrm{~m}$. Otras de menores elevaciones son de clima seco y se describen bajo bosque bajo abierto. Los climas van de semifríos húmedos y templado subhúmedos en todas sus variantes de humedad hasta semicálidos subhúmedos.

Entre sus componentes destacan árboles de Pinus y de Quercus. Dada la amplia diversidad de ambientes donde se presentan este tipo de bosques y el hecho de que muchas especies de esos géneros muestran preferencias ecológicas similares, estos bosques están representados por asociaciones muy diversas, en todos los grados intermedios entre el pinar puro y el encinar puro, razón por la cual muchos autores funden en sus estudios a los bosques de Pinus y los de Quercus (Rzedowski, 1978), por ejemplo Rzedowski y McVaugh (1966) y Challenger y Soberón (2008). La composición y las proporciones de las especies varían dependiendo de diversos factores ambientales y para el estrato arbóreo se registran desde dos hasta nueve especies (Márquez-Linares y González-Elizondo, 1998; Márquez Linares et al., 1999).

Algunos ejemplos de bosque de pino-encino de la SMO son los siguientes:

Hacia el norte, los pinos dominantes son los ya mencionados para el bosque de pino, combinados con encino. Destacan $P$. arizonica y $P$. engelmanii o, en sitios con mayor humedad ambiental, $P$. strobiformis. Entre los encinos, en el norte son comunes $Q$. rugosa y $Q$. gambelii. En áreas de mayor humedad ambiental $P$. duran- 
gensis. En Sonora, la cima de la Sierra de La Madera presenta Pinus arizonica, $P$. engelmannii, P. chihuahuana, Quercus arizonica y $Q$. hypoleucoides.

Otras asociaciones en climas semifríos son las de Pinus teocote, P. leiophylla, $P$. cooperi, $P$. durangensis y/o $P$. strobiformis con Quercus rugosa, $Q$. sideroxyla y/o Q. crassifolia. En Chihuahua y Durango, están los de Pinus chihuahuana, P. arizonica, Quercus rugosa, Q. durifolia, Juniperus deppeana y Arbutus spp. En condiciones de mayor humedad ambiental se presentan ailes o alisos (Alnus jorullensis y A. acuminata), capulín (Prunus serotina), alamillo o álamo temblón (Populus tremuloides) y cahuites (Pseudotsuga y Abies). En el estrato arbustivo están el táscate (J. deppeana), la manzanita (A. pungens), el madroño enano (Arbutus occidentalis) y especies de Ceanothus, Ribes, Rubus, Vaccinium y Pernettya.

Los madroños son comunes, particularmente Arbutus bicolor y A. madrensis en climas templados y fríos, $A$. arizonica en los templados semisecos, A. tessellata en los templado-cálidos y A. xalapensis en los templado húmedos, además del madroño enano $A$. occidentalis en bosques semifríos. Entre los táscates o cedros el más común es Juniperus deppeana, aunque también se presentan J. flaccida (en climas templado cálidos), J. durangensis (en sitios con sequía edáfica), además de J. blancoi var. mucronata y J. scopulorum en el norte del área.

Pinus cooperi y/o Pinus leiophylla con Q. sideroxyla y/o J. deppeana, Arbutus madrensis, A. arizonica, A. bicolor o Populus tremuloides se asocian en los alrededores de bajíos y partes bajas de laderas entre 2380 y $2900 \mathrm{~m}$.

Sobre collados o parteaguas, laderas y mesas entre 2500 y $2700 \mathrm{~m}$ Pinus teocote se acompaña de P. arizonica, P. engelmannii, P. leiophylla, Quercus sideroxyla, $Q$. arizonica, $Q$. mcvaughii, $Q$. laeta y madroños como Arbutus madrensis, A. arizonica y A. tessellata. En áreas relativamente secas se presentan Quercus arizonica, $Q$. emoryi y $Q$. durifolia, con frecuencia combinados con Pinus engelmannii o con P. teocote. Los nombres de Quercus laeta y Q. arizonica se aplican a un complejo de encinos blancos que es todavía pobremente entendido desde el punto de vista taxonómico, el cual presenta un marcado polimorfismo, fuerte introgresión y una gran amplitud ecológica.

En laderas con escasa pendiente y valles intermontanos en elevaciones medias se registran: a) Pinus durangensis, Q. rugosa y Q. sideroxyla con Arbutus madrensis, A. arizonica y escasos Alnus y Prunus; en algunos sitios se asocian también P. leiophylla, P. ayacahuite y A. tessellata. b) Quercus rugosa, P. teocote, P. ayacahuite, Pinus sp., Arbutus bicolor con Cupressus, $Q$. mcvaughii y A. arizonica. c) Quercus rugosa, Q. sideroxyla, Cupressus y P. ayacahuite con Arbutus bicolor, Pseudotsuga, Fraxinus, Pinus durangensis y Pinus discolor. d) Quercus crassifolia, 
Arbutus bicolor, P. teocote con Pinus durangensis, Q. sideroxyla, P. ayacahuite, Arbutus arizonica, Cupressus, Q. rugosa, Garrya.

Hacia el declive oriental Quercus durifolia es abundante en sitios con suelo profundo y escasa pendiente (mesas y bajíos) entre 1900 y $2600 \mathrm{~m}$, con Pinus cooperi, P. leiophylla o P. engelmannii o formando encinares puros.

Pinus discolor se conoce desde el Archipiélago Madrense y el norte de la sierra hasta el centro de Durango, en poblaciones más bien pequeñas y disyuntas.

En Chihuahua y el norte de Durango entre los 2280 y $2400 \mathrm{~m}$ se localiza Quercus tarahumara, un encino roble de distribución restringida que crece principalmente sobre suelos someros, hidrotérmicamente alterados.

Hacia el este de Sonora existen bosques con $P$. engelmannii, $P$. yecorensis, $P$. chihuahuana y $P$. herrerae y varias especies de Quercus: $Q$. arizonica, $Q$. chihuahuensis, $Q$. durifolia, $Q$. hypoleucoides, $Q$. jonesii, $Q$. oblongifolia y $Q$. toumeyi, con ocasionales Juniperus deppeana, Arbutus sp. (Van Devender et al., 2003; Ortega-Rosas et al., 2008a) y Juniperus blancoi var. mucronata. En Chihuahua, entre 2000 y 2300 m en el Parque Nacional Cascada de Basaseachi se combinan en diversas asociaciones: Pinus chihuahuana, $P$. durangensis, $P$. engelmannii, $P$. herrerae, $P$. strobiformis, $Q$. jonesii, $Q$. mcvaughii, Q. rugosa, Cupressus lusitanica, Arbutus arizonica, A. xalapensis, Arctostaphylos pungens y Comarostaphylis polifolia. Más al sur, Pinus durangensis convive con Quercus sideroxyla y/o Q. rugosa, $P$. strobiformis y algunas de las especies mencionadas en el párrafo anterior.

En la Sierra Fría, en Aguascalientes, se asocian Pinus leiophylla, Quercus jonesii y Quercus eduardii en comunidades abiertas.

En sitios de suelo muy somero y afloramientos de toba o riolita intemperizados son comunes asociaciones de pino triste (Pinus lumholtzii) con cucharillo o encino roble (frecuentemente Quercus radiata, a veces $Q$. urbanii y/o $Q$. rugosa) o con $Q$. jonesii. Entre los elementos arbustivos destacan la manzanita (A. pungens), el cedro chino (Juniperus durangensis) y el madroñito (Comarostaphylis polifolia). En el mismo tipo de hábitat, sobre la vertiente oriental de la sierra puede desarrollarse una asociación de Quercus jonesii con Pinus teocote y P. chihuahuensis, o con $P$. lumholtzii, Q. laeta, Arbutus y Crataegus (ej. al E de Topia, entre 2000 y 2100 m).

En la subregión Madrense Tropical, entre 1400 y 2400 m, se presentan Pinus oocarpa, P. douglasiana, P. devoniana, Pinus herrerae, P. maximinoi, P. lumholtzii, P. luzmariae, Quercus crassifolia y otras especies termófilas de Quercus, así como Arbutus tessellata, A. madrensis y/o A. xalapensis. Ocasionalmente, especies de la vertiente interior, como $P$. engelmannii y $P$. leiophylla también se encuentran presentes. En Chihuahua, entre 1900 y 2000 m existen Quercus viminea, Q. arizonica, 
Pinus douglasiana, P. engelmannii, P. maximinoi, Arbutus arizonica y A. tessellata, mientras que entre 1700 y 1800 m, en cañadas húmedas, están Pinus durangensis y Quercus hypoleucoides con Tilia y Abies.

En sitios con alta humedad ambiental se desarrollan bosques de encino-pino intermedios con el bosque mesófilo, destacando Pinus maximinoi, $P$. devoniana, $P$. pseudostrobus y/o $P$. herrerae, Quercus candicans, $Q$. splendens y $Q$. subspathulata, $Q$. scytophylla, $Q$. crassifolia, $Q$. viminea (encino duraznillo, cusi saucillo), Prunus serotina y Arbutus xalapensis. Pinus maximinoi es abundante en laderas y cañadas mientras que $P$. herrerae es común en mesas y en partes altas de las laderas. Alnus, Garrya y Cornus son componentes de los bosques mixtos en sitios con mayor humedad ambiental (González Elizondo et al., 2007).

En el sur de Sinaloa, entre 1600-1700 m, existe bosque de encino-pino de Quercus subspathulata y Pinus oocarpa, con Befaria mexicana (Carrillo-Reyes et al., 2003). También en Sinaloa, en elevaciones alrededor de 2000 m, se encuentran Pinus herrerae, P. maximinoi, P devoniana, con Quercus spp. y Arbutus tessellata.

En Jalisco, a 1700 m, se registran Quercus resinosa Liebm., Quercus praineana Trel. y $P$. oocarpa. Entre los elementos leñosos y rosetifolios de bosques de pinoencino de influencia tropical en Jalisco se registran Comarostaphylis glaucescens (Kunth) Zucc. et Klotz., Agarista mexicana (Hemsl.) Judd var. pinetorum (Standl. et Wms.) Judd, Acacia pennatula (Schltdl. et Cham.) Benth., Dodonaea viscosa Jacq. y Clethra rosei Britton (Carrillo-Reyes et al., 2003).

De interés biogeográfico por incluir a Pinus maximartinezii son dos comunidades, una al sur de Durango y otra al sur de Zacatecas, en las que Quercus resinosa Liebm. y Pinus lumholtzii se acompañan de P. maximartinezii, $Q$. chihuahuensis Trel., Q. praeco Trel., Fraxinus aff. velutina Torr., Arbutus tessellata Sorensen y, en cañadas, Quercus gentryi C.H. Muller.

\section{4. Bosque de encino}

Engloba a una amplia gama de comunidades de composición florística, estructura y afinidades ecológicas muy diferentes, cuyo rasgo común es la dominancia de especies arbóreas de Quercus (Rzedowski, 1978). Cubre casi 14\% de la superficie de la $\mathrm{SMO}$, desde los $340 \mathrm{~m}$ s.n.m. sobre lomeríos rodeados por bosque tropical caducifolio, hasta los $2900 \mathrm{~m}$ en zonas frías de la sierra. Climas: templado subhúmedo, semicálido subhúmedo y semiseco templado con temperaturas medias anuales de 12 a más de 18 ${ }^{\circ} \mathrm{C}$, precipitación anual promedio entre 700 y $1700 \mathrm{~mm}$. La época seca va de 0 a 9 meses.

Los encinares en la SMO están representados por tres tipos principales: a) los de bosque bajo abierto (descritos bajo el ecosistema Madrense xerófilo), b) los de cli- 
mas templados en el macizo de la sierra; y c) los bajos y abiertos de afinidad tropical. Muchas de las comunidades representadas en el mapa de vegetación como bosque de encino corresponden a comunidades de bosque bajo abierto de clima semiárido o a las comunidades de bajas elevaciones intercaladas entre la vegetación tropical.

Destacan las siguientes asociaciones de bosque de encino:

Quercus sideroxyla y/o Q. rugosa, desde los (1700-) 2000 hasta los $2900 \mathrm{~m}$. Quercus rugosa llega a formar comunidades puras en sitios con alta humedad ambiental o se asocia con otros encinos y con pinos. Quercus sideroxyla se desarrolla en bajíos, cañadas y laderas de escasa pendiente, por lo general sobre suelos profundos. En bosques húmedos en climas más fríos $Q$. sideroxyla y $Q$. rugosa pueden comportarse como perennifolias. Quercus durifolia llega a formar encinares puros en sitios más o menos planos, entre 1900 y $2600 \mathrm{~m}$.

Otras especies de encino que son abundantes hacia el declive occidental de la Sierra Madre, ya sea en bosques de encino o en bosques mixtos están Quercus fulva (1900 a $2400 \mathrm{~m}) ;$ Q. mcvaughii (2100 a $2700 \mathrm{~m})$ y Q. scytophylla (1700 a 2700 m). Quercus laeta, un encino blanco, es uno de los encinos con mayor tolerancia ecológica. Se desarrolla desde los 1400 hasta los $2700 \mathrm{~m}$ particularmente en la vertiente occidental y en el sur de la SMO, a veces como dominante en encinares o en bosques mixtos.

En la zona Madrense Tropical, entre 1500 y $2800 \mathrm{~m}$ hay encinares subcaducifolios con características similares a las del bosque mesófilo donde destacan Quercus candicans, $Q$. crassifolia, $Q$. diversifolia, $Q$. scytophylla y Clethra spp. Alcanzan una altura de 20 a $25 \mathrm{~m}$ y presentan abundantes epifitas, principalmente del género Tillandsia y orquídeas.

Otros encinares del declive hacia el Pacífico forman una franja de transición entre los bosques de coníferas o de pino-encino y los bosques de tipo tropical: el encino duraznillo ( $Q$. viminea) es dominante en encinares y en bosques mixtos entre 1400 y los 2510 m. Entre 1400 y 2200 m, en clima cálido subhúmedo, se desarrollan bosques de $Q$. subspathulata. En áreas intermedias con el bosque tropical caducifolio están Quercus cf. castanea $(1500$ a 1700 m), Q. diversifolia $(1400$ a 1700 m) y Q. gentryi (1400 a $2100(-2600 \mathrm{~m}))$.

Los encinares de las partes más bajas de la vertiente occidental (340 a 1400 m) incluyen muchas especies termófilas y por lo general ocupan partes altas adyacentes a los bosques tropicales. Quercus albocincta es el que se desarrolla a menores elevaciones, seguido por $Q$. chihuahuensis y $Q$. tuberculata. Hacia el sur de la sierra, sobre suelos pedregosos en Aguascalientes, Zacatecas, norte de Jalisco y sur de Durango, destacan los bosques bajos, por lo general abiertos, de árboles de hoja 
decidua como los robles (Q. magnoliifolia y $Q$. resinosa), a veces con $Q$. eduardii y $Q$. viminea. Muchas de estas comunidades están siendo substituidas por matorrales de Dodonaea. En sitios abiertos y secos se localiza un encino blanco (Quercus cf. chihuahuensis). De los $1150 \mathrm{~m}$ de elevación hacia arriba se encuentran también $Q$. jonesii y $Q$. laeta, ya sea en encinares puros o en bosques mixtos con Pinus oocarpa, $P$. lumholtzii o $P$. luzmariae. Los encinares caducifolios de la vertiente occidental llegan a presentar abundantes orquídeas epífitas, entre las que destaca Laelia speciosa.

Los encinares de climas semisecos con Quercus oblongifolia, Q. emoryi, $Q$. chihuahuensis, $Q$. grisea, $Q$. arizonica y $Q$. eduardii se discuten con el Bosque bajo abierto.

\section{5. Bosque mesófilo de montaña}

Cubre apenas $0.14 \%$ de la superficie de la sierra, sobre la vertiente occidental, en elevaciones entre los 1000 y los $2350 \mathrm{~m}$, con unos pocos manchones hasta los 700 $\mathrm{m}$. Clima templado húmedo y templado subhúmedo en su variante de mayor humedad así como semicálido subhúmedo; durante la mayor parte del año la humedad ambiental es muy alta ya sea por lluvia o por condensación de neblinas; libres de heladas o con ligero descenso de $0^{\circ}$. Se restringe a cañadas, laderas suaves y pequeños valles en sitios protegidos, donde persiste la humedad proveniente del Pacífico.

Forman manchones pequeños y muy localizados y a veces es difícil separarlos de otros bosques húmedos, particularmente de algunas comunidades de pino-encino y bosques mixtos de coníferas. Al igual que los encinares, los bosques mesófilos difieren ampliamente en composición florística y estructura, pero en general son muy ricos en diversidad biológica y en complejidad estructural (Rzedowski, 1978). En términos comparativos con otros bosques mesófilos de México, denominados también bosques húmedos de montaña (Villaseñor, 2010), los de la SMO son estructuralmente menos complejos.

Entre sus elementos característicos o indicadores están el corpo o magnolia (Magnolia pacifica A. Vázquez subsp. tarahumara A. Vázquez) en Sinaloa y Durango, Styrax ramirezii, cedro (Cedrela odorata), guapaque (Ostrya virginiana), tilo (Tilia americana var. mexicana) y Lauráceas como los aguacatillos (Persea liebmannii, P. podadenia), Nectandra, y otras. Entre los encinos destacan Q. candicans, Quercus crassifolia, $Q$. castanea, $Q$. rugosa, $Q$. scytophylla y $Q$. splendens. Otras especies que se comparten con bosques templados húmedos de la SMO son el madroño (Arbutus xalapensis), palo prieto (Garrya laurifolia), Cornus disciflora, C. excelsa, laurel (Litsea glaucescens), Litsea spp., madroños de agua (Clethra spp.), capulín 
(Prunus sp.), Peltostigma pteleoides, Ilex quercetorum, I. tolucana, huencho (Cleyera integrifolia), y la palma Brahea aculeata. Con frecuencia participan también coníferas como Pinus maximinoi, $P$. devoniana, $P$. douglasiana, $P$. herrerae, $P$. strobiformis, $P$. durangensis, Abies neodurangensis o Pseudotsuga menziesii. Como árboles más bajos se presentan Agonandra racemosa, Aralia sp., Oreopanax echinops, O. peltatus, Cercocarpus macrophyllus y Ternstroemia spp., mientras que en el estrato arbustivo destacan Coriaria, Triumfetta, Cornus, Rhus y Monnina.

Los bosques mesófilos de distribución más boreal en México son los de la Sierra de Las Ventanas (Durango-Sinaloa). Aunque este tipo de vegetación no alcanza la latitud de Sonora y Chihuahua, varios de sus elementos llegan a esas latitudes. Por ejemplo, Van Devender et al. (2010) registran haya (Cinnamomum hartmannii), laurel cimarrón (Persea podadenia), magnolia (Magnolia pacifica subsp. tarahuma$r a$ ), papaya cimarrona (Oreopanax peltatum) y cortopico (Drypetes gentryi Monach.). Bosques intermedios entre el mesófilo y el mixto de coníferas se conocen de Chihuahua (Madera, Ocampo) entre los 2400 y 2500 m, en donde Abies, Pinus y Pseudotsuga se mezclan con Acer, Tilia, Arbutus y Quercus.

En Durango y Sinaloa Ostrya virginiana se combina con Tilia, Quercus, Pinus maximinoi, Ilex, Oreopanax y Arbutus xalapensis. El cedro (Cedrela odorata) se registra desde bajas elevaciones hasta los $2100 \mathrm{~m}$, creciendo cerca de Abies neodurangensis. En algunas cañadas Tilia es el árbol dominante, con escaso Quercus scytophylla. En el estrato arbustivo destacan Rhamnus betulaefolia y Oreopanax echinops. En sitios cercanos Q. scytophylla pasa a ser dominante, con abundantes epífitas como Tillandsia, líquenes y hemiparásitas colgantes gigantes como Phoradendron y Cladocolea. En Sinaloa se presenta también álamo o aliso (Platanus gentryi) y nogal (Juglans major), mientras que en la región de barrancas del sur de Zacatecas y norte de Jalisco Magnolia pugana alcanza a entrar a la SMO.

Los bosques mesófilos de las barrancas del sur de Durango y Zacatecas, noreste de Nayarit y sureste de Sinaloa (Huajicori, Sierra del Nayar y Sierra San Pedro) presentan un buen nivel de conservación y buena continuidad en la cobertura, con árboles como el carpo (Carpinus caroliniana), mimbre pasilla (Cornus disciflora), magnolia (Magnolia pacifica) y guapaque (Ostrya virginiana), entre otras. El estrato arbóreo inferior (10- $17 \mathrm{~m}$ de altura) está representado principalmente por mameyito (Saurauia serrata), guayabillo (Clusia salvinii), malvaste (Clethra rosei) y encino (Quercus castanea) (Baab et al., 2010).

Para el norte de Jalisco Luquín et al. (2004) citan a Oreopanax peltatus, Abies durangensis, Ilex rubra, Cornus disciflora, Clethra rosei, Quercus laurina, Q. crassifolia y $Q$. obtusata. 


\section{6. Otras comunidades}

\section{6. 1. Chaparral secundario}

Los chaparrales de la SMO son matorrales usualmente muy densos, cuyos elementos dominantes son arbustos esclerófilos, perennifolios, como la manzanita o pingüica (Arctostaphylos pungens) y/o el charrasquillo (Quercus depressipes), acompañados de Garrya wrightii y otros elementos cuyas hojas coriáceas les confieren resistencia a los vientos desecantes y a incendios de baja intensidad. Estos chaparrales pueden representar vegetación primaria o secundaria. Los de tipo primario se describen para la subregión Madrense Xerófila; sin embargo, dentro del macizo de la sierra existen chaparrales sobre afloramientos rocosos intemperizados o en laderas y collados afectados por vientos intensos y desecantes, los cuales pudieran también representar chaparrales primarios.

Los chaparrales de tipo secundario se presentan en el macizo de la SMO entre los 2300 y 3000 m s.n.m. Se desarrollan en climas templados y templado semi-fríos, en sitios donde el bosque ha sido eliminado o reducido, siendo con frecuencia favorecidos por fuego o por desmontes. A veces persisten individuos relictuales de la vegetación de bosque que fue substituida (usualmente pinos). La cuantificación de poco más de $0.8 \%$ de la superficie de la SMO para los chaparrales secundarios representa muy probablemente una cifra subestimada debido a que con frecuencia estas comunidades cubren superficies relativamente pequeñas que no se registran a la escala de 1:250 000 a la que los datos fueron analizados en este trabajo.

Por su fisonomía, el chaparral madrense presenta similitud con el chaparral de Baja California y el extremo suroeste de Estados Unidos, pero difiere en aspectos florísticos, en su respuesta al fuego y en el tipo de clima en el que se desarrolla: templado con lluvias en verano en la SMO vs mediterráneo con verano seco y lluvias en invierno. Una comparación entre los chaparrales mexicanos de clima no-mediterráneo con chaparrales de clima mediterráneo en otras partes del mundo (ValienteBanuet et al., 1998) revela más similitudes que diferencias entre estos; en el mismo trabajo se concluye que tanto las características de los chaparrales mexicanos (a los que denominan mexical), como su distribución a lo largo de los flancos a sotavento de las montañas de México, apoyan la hipótesis del origen Madro-Tetiano propuesta por Axelrod (1975). Axelrod (1958) ya había hecho notar la estrecha relación entre los chaparrales californianos y los del centro de Arizona.

Así, el chaparral madrense presenta tanto similitudes como diferencias con los de tipo mediterráneo. Las discrepancias se aprecian particularmente en sus adaptaciones al fuego, ya que la estrategia del principal componente del chaparral ma- 
drense y del chaparral mexicano no-mediterráneo en general (A. pungens) es una abundante producción de frutos y dispersión mediante diferentes mecanismos (Márquez Linares et al., 2005, 2006), mientras que los arbustos del chaparral californiano se dividen en tres grupos por sus estrategias de regeneración post-fuego (Cowan y Ackerly, 2009), siendo común la regeneración por rebrote; aunque A. pungens también llega a formar parte del chaparral californiano, en este prevalecen las especies con otros mecanismos de regeneración.

En la SMO, el incremento en la densidad de A. pungens se ve favorecido por incendios frecuentes de intervalos cortos (Márquez Linares et al., 2006). Debido a su tolerancia al fuego, acidificación del suelo y densidad, una vez establecidos los chaparrales de $A$. pungens no permiten el establecimiento de plántulas de pinos durante varias décadas (Casas et al., 1995).

\section{6. 2. Vegetación de claros en bosque templado}

En valles intermontanos con suelos profundos pero de drenaje deficiente, la alta humedad edáfica impide el desarrollo de árboles, los cuales se presentan solamente en los márgenes, rodeados de bosques de pino o de pino-encino. Estos claros se encuentran entre los 2300 y 3100 m s.n.m., cubiertos por comunidades de herbáceas entre las que predominan diversas Asteráceas, Gentianáceas, Poáceas y Ciperáceas. Tanto estos claros, como los encontrados en las cimas de las montañas más altas (entre los 3200 y 3340 m), albergan una alta proporción de endemismos para la SMO.

En claros ubicados en el fondo de pequeños valles son comunes los sitios que se encharcan durante varios meses del año, en los cuales se desarrolla vegetación de ciénega. En estas ciénegas de bajíos inundables son comunes especies de los géneros Carex, Cyperus, Eleocharis, Eryngium, Equisetum, Juncus, Luzula, Agrostis, Mimulus, Hydrocotyle, así como Chromolepis heterophylla.

Entre las especies acuáticas o subacuáticas endémicas a este tipo de hábitats se cuentan: Sisyrinchium cholewae, Senecio billieturneri, Trichocoryne connata, Jaegeria spp., Coreopsis maysillesii, Olivaea leptocarpa, Carex durangensis (González Elizondo et al., 2007), así como Hydropectis aquatica, Pectis sp. y Polygonum spp.

En claros de bosque de clima templado-cálido son frecuentes las asociaciones de Cyperus, Eleocharis, Juncus, Agrostis, Echinochloa, Polypogon, Paspalum, Polygonum y Ranunculus, entre otros géneros. Para Sonora, Ortega-Rosas et al. (2008a), describen a los elementos en la Ciénega de Camilo, un humedal con Sphagnum palustre con varias especies de Cyperaceae, Poaceae y Pteridofitas, en medio de bosque de pino-encino. 
Muchas de las ciénegas Madrenses han desaparecido o se han visto marcadamente reducidas en las dos décadas recientes debido a desecación natural o artificial, siendo substituidas por cultivos de avena.

\section{6. 3. Comunidades de cimas de montañas}

Aunque la SMO no presenta comunidades de vegetación alpina, en las cimas de los picos más altos (Cerro Gordo, Mohinora, Huehuento y otros), por encima de los 3200 m existe vegetación herbácea baja (plantas enanas de Sedum, Draba, Senecio, Poa, Bouteloua, Muhlenbergia), así como líquenes y musgos, característicos de vegetación subalpina (González Elizondo et al., 2007). Protegidas entre los arbustos hay otras especies herbáceas como Heuchera, Primula y Saxifraga. En el Cerro Gordo, Huehuento y Mohinora destaca la presencia de un arbusto postrado (Juniperus blancoi var. huehuentensis) (Adams et al., 2006; Mastretta-Yanes et al., 2011). En los Cerros Gordo y Mohinora algunos individuos de pino alcanzan la parte alta, pero en general la cima carece de árboles. Su ausencia en estos casos está determinada por el efecto de los vientos desecantes más que por las bajas temperaturas.

Una similitud florística sorprendentemente baja entre las cimas de tres los picos más altos de la SMO (Cerro Gordo, Huehuento y Cerro de las Antenas) es reportada por Ruacho González (2011), donde de un total de 175 especies, únicamente dos se comparten por los tres cerros. McDonald et al. (2011) también hacen notar el bajo índice de similitud entre la flora de la cima del Cerro Mohinora y otros picos

de México y el sur de Estados Unidos, lo que revela el largo aislamiento de la flora del Mohinora.

\section{MADRENSE-XERÓFILA}

Esta región se ubica en el piedemonte norte y oriental de la sierra y en las estribaciones al oriente, entre los 1200 y $2500(-2800) \mathrm{m}$, con climas secos y templados. Presenta bosques bajos abiertos, matorrales perennifolios y zonas de ecotonía hacia pastizal y matorral xerófilo, además de ecotonías con matorral subtropical hacia el sur del Archipiélago Madrense.

\section{1. Bosque bajo abierto}

Cubre más de $13 \%$ de la superficie de la SMO, en el piedemonte oriental y las estribaciones al norte. Se presenta entre los 1450 y los $2500 \mathrm{~m}$ s.n.m., alcanzando hasta $2800 \mathrm{~m}$ en las partes altas de serranías aisladas en Durango y Zacatecas. El clima es semiseco templado y en menor proporción templado subhúmedo de baja humedad; 
lluvias en verano, con precipitación anual de 600 a $800 \mathrm{~mm}$. Son comunidades muy diversas, ya sea de encino, pino-encino o pino, con árboles usualmente de menos de $6 \mathrm{~m} \mathrm{y}$ muy espaciados (desde 10\% de cobertura) o con dosel más o menos denso (hasta $80 \%$ ).

Los dominantes fisonómicos del bosque bajo abierto (Pinus cembroides y varias especies de Quercus) son los mismos independientemente del grado de cobertura del dosel, la cual se vincula básicamente con condiciones ambientales más favorables. El estrato herbáceo es denso, dominado por gramíneas. El bosque bajo abierto representa comunidades de transición entre los bosques de pino-encino y los pastizales y matorrales xerófilos al oriente y al norte de la SMO, por lo que incluye con frecuencia elementos xerófilos como Opuntia, Agave y Yucca.

En el norte de Sonora y Chihuahua estas comunidades presentan encinos y coníferas de afinidad xerófila (piñoneros y táscates). El encino azul (Quercus oblongifolia), encino rojo (Quercus emoryi), y el encino blanco (Q. arizonica) son con frecuencia monodominantes, o pueden asociarse entre sí y con piñonero (Pinus cembroides), pino chino (P. chihuahuana), encinos blancos (Quercus grisea, Q. chihuahuensis), madroño (Arbutus arizonica) y/o táscate (Juniperus deppeana). Hacia mayores elevaciones aparece también Quercus hypoleucoides y hacia el occidente $Q$. viminea, mientras que hacia las zonas de ecotono con matorral perennifolio se asocia también Juniperus coahuilensis.

En Chihuahua, Durango y Zacatecas son comunes las asociaciones de Pinus cembroides y Juniperus deppeana con o sin encinos, ocasionalmente con Garrya wrightii, Rhus aromatica, $R$. virens, Citharexylum altamiranum y Agave parryi. Hacia mayores elevaciones aparece $P$. chihuahuana mientras que en el declive hacia el altiplano hay amplias franjas de ecotonía con matorral xerófilo en los que Acacia schaffneri, Opuntia spp. y Yucca decipiens se integran al bosque bajo abierto. En sitios sobrepastoreados de ecotonías hacia el pastizal son comunes el gatuño (Mimosa biuncifera y M. dysocarpa) y sotol (Dasylirion).

Algunos bosques bajos abiertos son encinares. En el piedemonte oriental estos son de aspecto sabanoide, en una amplia ecotonía con la franja de pastizal. Entre sus principales componentes arbóreos están $Q$. grisea y $Q$. chihuahuensis en las partes más bajas, a veces también con $Q$. conzattii. En sitios perturbados, los bosques bajos de encino están siendo reemplazados por matorrales de jarilla (Dodonaea viscosa), la cual está convirtiéndose en un elemento común en el estrato arbustivo del bosque bajo abierto (González Elizondo et al., 2007). Otros encinares bajos abiertos son los de $Q$. emoryi, a veces con $Q$. oblongifolia desde el norte de la sierra hasta poco más al norte del paralelo $24^{\circ} \mathrm{N}$ y los de $Q$. eduardii desde esa latitud hasta el sureste de la sierra, con introgresión entre ambas especies en la zona de contacto. 
En las Barrancas del Cobre, entre los 1700 y 1900 m s.n.m. en la Baja Tarahumara en Chihuahua existen bosques bajos con Quercus oblongifolia, Q. toumeyi, Q. chihuahuensis y arbustos como Garrya ovata y Bouvardia ternifolia. Hacia sitios más húmedos aparecen G. laurifolia, Rhamnus betulifolia, Ceanothus depressus, Prunus gentryi y P. serotina (Lebgue Keleng, 2002).

Los encinares bajos y abiertos de climas semicálidos del declive occidental son comentados bajo el apartado de bosques de encino.

\section{2. Matorral perennifolio}

Con aproximadamente $0.14 \%$ de la superficie, se localiza en el piedemonte, laderas suaves y terrenos planos de la región norte y oriente, entre los 1500 y 2300 $\mathrm{m}$ de altitud, en transición con bosque bajo abierto hacia arriba y con la franja de pastizal o con matorral xerófilo hacia abajo.

Son comunidades dominadas por táscates (principalmente Juniperus coahuilensis), con frecuencia asociados con Rhus (Rhus virens, R. aromatica), el cual llega a ser dominante en algunos sitios. En cañadas se encuentran también rosáceas arbustivas esclerófilas como Lindleya mespiloides, Malacomeles psilantha, Cercocarpus fothergilloides var. mojadensis, C. montanus, Purshia mexicana, $P$. plicata, Vauquelinia californica y $V$. corymbosa. En ecotonía con el matorral xerófilo, Juniperus se asocia con Yucca, Mimosa, Acacia neovernicosa, A. schaffneri y Berberis trifoliolata y muchos de sus componentes herbáceos son los mismos que se encuentran en el matorral y el pastizal (González Elizondo et al., 2007).

Las comunidades de $J$. deppeana var. zacatecensis que usualmente crece como arbusto en áreas abiertas en bajíos de bosques templados, con suelo de drenaje pobre o en sitios donde el pino ha sido eliminado por fuego, pueden considerarse como una variante de matorral perennifolio.

\section{3. Chaparral}

Los chaparrales de tipo primario se desarrollan en las estribaciones y serranías derivadas de la SMO hacia el oriente, con clima semiseco templado, continental y de lluvias de verano (a diferencia de los chaparrales californianos y del extremo noroeste de México). Cubren aproximadamente $0.24 \%$ de la superficie, entre los 1900 y los $2500 \mathrm{~m}$ de altitud, en laderas o collados con fuerte afloramiento de roca ígnea o sobre suelos someros.

Se trata de matorrales usualmente densos, perennifolios, esclerófilos, dominados por manzanita (Arctostaphylos pungens) y/o por charrasquillo (Quercus 
depressipes), con otros arbustos como Garrya wrightii, Cercocarpus montanus, Comarostaphylis polifolia y Amelanchier. Las hojas coriáceas les confieren resistencia a los vientos desecantes y a períodos prolongados de sequía. Los elementos de chaparral constituyen a veces el estrato arbustivo de bosques muy abiertos de pino piñonero (Pinus cembroides). Uno de los dos géneros endémicos de Durango, $\mathrm{Me}$ gacorax, se conoce de este tipo de comunidades en la Sierra de Coneto (GonzálezElizondo et al., 2002).

Arctostaphylos pungens tiene una amplia tolerancia ecológica y juega diferentes papeles. Puede ser dominante en chaparrales de tipo primario en sitios con baja humedad ambiental o edáfica (Casas et al., 1995). Puede también formar parte del sotobosque en bosques no perturbados, o formar densas cubiertas (chaparral secundario) en sitios previamente ocupados por bosque, en cuyo caso depende del fuego para su renovación (Márquez Linares et al., 2006). En muchos aspectos, Quercus depressipes se comporta de modo similar.

\section{4. Pastizal halófilo}

Cubre áreas reducidas ( $0.03 \%$ de la superficie de la SMO) entre los 2000 y $2200 \mathrm{~m}$ s.n.m., en el fondo de grandes valles intermontanos entre las ramificaciones que la SMO presenta hacia el norte.

En el valle de San José de Babícora o Gómez Farías, al centro-occidente del Estado de Chihuahua, se localiza una laguna endorreica rodeada de pastizal halófilo en el que predominan Sporobolus airoides, Distichlis spicata, Hopia obtusa y Pleuraphis mutica; en áreas menos alcalinas destacan Bouteloua gracilis y especies de Aristida, Muhlenbergia, Eragrostis y Chloris. Una lista florística para esta área se registra por Estrada-C. et al. (1997). Las planicies adyacentes son utilizadas como terrenos agrícolas, que a su vez están rodeados por mosaicos de vegetación natural entre los que destacan el matorral de Juniperus y bosque bajo abierto de Pinus cembroides en algunas áreas y de Pinus-Quercus en otras.

\section{5. Pastizal, Matorral xerófilo y Bosque xerófilo espinoso}

Por tratarse de tipos de vegetación del altiplano y no de la Sierra Madre Occidental, se consideran aquí solamente las pequeñas áreas donde estos presentan ecotonía con comunidades de la sierra.

\section{5. 1. Pastizal}

Se presenta desde los $1200 \mathrm{~m}$ de altitud en el norte del área hasta los 2200 en la parte sur, en zonas planas o de topografía ligeramente ondulada. Clima semiseco 
templado y seco templado, con precipitación media anual de entre 300 a $600 \mathrm{~mm}$, con 6 a 9 meses secos y heladas frecuentes.

Son comunidades dominadas por plantas herbáceas, principalmente gramíneas. No hay árboles excepto a lo largo de corrientes de agua pero con frecuencia existen arbustos espaciados.

Son frecuentes las comunidades de Bouteloua gracilis, B. curtipendula y Aristida con Lycurus, Botriochloa, Setaria, Muhlenbergia y Trachypogon. En partes más altas y en ecotonía con el bosque bajo abierto la asociación que predomina es de Bouteloua-Heteropogon (o Heteropogon-Bouteloua) en terrenos pedregosos. Entre los arbustos están Rhus virens, Acacia, Prosopis, Opuntia y Mimosa, la cual se vuelve abundante en áreas sobrepastoreadas. Hacia el ecotono con matorral perennifolio hay Juniperus.

\section{5. 2. Matorrales xerófilos}

Se conocen desde los $1000 \mathrm{~m}$ en Sonora hasta los $2250 \mathrm{~m}$ en Zacatecas. Los del norte incluyen elementos tanto del desierto Sonorense como del desierto Chihuahuense que llegan a las bases de las sierras del Archipiélago Madrense y al piedemonte del norte de la SMO. En latitudes medias, el piedemonte de la SMO en Durango presenta elementos de matorral de Acacia schaffneri, opuntias arborescentes (Opuntia durangensis, O. leucotricha y otras) y Yucca decipiens.

En el sureste (Durango-Zacatecas), sobre suelos someros, con frecuencia basálticos, los matorrales pueden ser crasicaules, de Opuntia leucotricha, O. durangensis y/o O. streptacantha.

\section{5. 3. Bosque xerófilo espinoso}

Se presenta en las partes bajas, entre 1800 y $1900 \mathrm{~m}$ de altitud y ocupa menos de $0.4 \%$ de la superficie del área, sobre terrenos aluviales y suelos profundos, asociados con frecuencia a un manto freático. Es una comunidad vegetal dominada principalmente por mezquite (Prosopis laevigata), a veces con huizache chino ( $\mathrm{Aca}$ cia schaffneri), de 5 a $10 \mathrm{~m}$ de alto en condiciones de humedad pero que en sitios más secos pasa a ser arbustiva.

\section{TROPICAL}

La vegetación tropical se desarrolla en las partes bajas y en las inmediaciones de la SMO e ingresa a través de las barrancas y quebradas de la vertiente occidental, entre 300 y 2000 m de altitud, en climas cálidos subhúmedos, semicálidos y secos cálidos. 


\section{1. Bosque tropical caducifolio}

Cubre extensas áreas adyacentes a la SMO. De la zona delimitada en este trabajo cubre aproximadamente $7 \%$ de la superficie, donde ocupa la mayor parte de la zona baja de las barrancas y quebradas al occidente y sur de la sierra y la base occidental de esta, entre los 200 y los 2000(-2160) m s.n.m. En su límite boreal de distribución en Sonora sube hasta los $1100 \mathrm{~m}$ pero en Durango y Zacatecas alcanza a llegar al interior a través de las grandes quebradas como la del río Mezquital, alcanzando los $2160 \mathrm{~m}$. Los climas predominantes son cálidos, aunque también hay semisecos; libres de heladas, con temperatura media anual $>20^{\circ} \mathrm{C}$, precipitación de 500 a $1200 \mathrm{~mm}$ y 6 a 9 meses de sequía, lo que propicia un cambio radical en el aspecto de las comunidades entre ambas temporadas ya que en buena parte del año el bosque presenta un aspecto seco en el que apenas se reconoce su afinidad tropical.

Está compuesto por árboles caducifolios de 4 a $15 \mathrm{~m}$ de alto, espaciados o densos. Debido a que este tipo de vegetación se desarrolla entre el piedemonte occidental de la sierra y la planicie costera noroccidental con continuidad latitudinalmente, la composición de las comunidades que lo representan desde Sonora hasta Nayarit y Jalisco es relativamente más uniforme que la de los bosques Madrenses. Aún así, difieren ampliamente en composición florística, fisonomía y afinidades ecológicas dependiendo de las condiciones ambientales donde se desarrollan. Las comunidades de menores elevaciones en Sonora, Sinaloa y Durango son llamadas "monte mojino" y en ellas destacan elementos de sucesión secundaria.

En laderas con fuerte insolación son comunidades bajas o medias (4 a 15 $\mathrm{m}$ ), de estructura irregular, con frecuencia dominadas por árboles espinosos (principalmente Leguminosas), entre las que destacan mautos y tepehuajes (Lysiloma spp.), huizache tepame (Acacia pennatula), huizache (Acacia farnesiana), Havardia spp., Pithecellobium spp., Enterolobium cyclocarpum, así como copales y copalillos (Bursera excelsa, B. collina, B. palmeri), papelillos y torotes (Bursera multijuga, B. fagaroides), palo mulato (Bursera grandiflora), cascalosúchil/sacalasúchil (Plumeria rubra), pochote (Ceiba acuminata), amapas (Tabebuia spp.), clavellín/cuajilote (Pseudobombax palmeri), Sapium spp., Sebastiania cornuta, guaje cirial (Crescentia alata), amolillo (Sapindus saponaria), haba (Hura polyandra), navío/palo joso (Conzattia sericea), cepillo (Combretum farinosum), Amphipterygium adstringens, palo torsal (Alvaradoa amorphoides), papelío (Jatropha cordata), Nopalea karwinskiana y cactáceas columnares como pitahaya (Stenocereus thurberi), etcho (Pachycereus pecten-aboriginum), Pilosocereus sp. y Stenocereus spp.

En Sonora, Chihuahua y el norte de Sinaloa, en su condición natural estos bosques presentan árboles de $10-15 \mathrm{~m}$ de alto y dosel que cubre $100 \%$ de la super- 
ficie (Felger y Johnson, 1995). Son abundantes los copales y torotes (Bursera spp.), guayacán (Guaiacum coulteri), diversas leguminosas como mauto (Lysiloma divaricatum), tepeguaje (Lysiloma watsonii), Conzattia multiflora, brasil (Haematoxylum brasiletto), palo pinto/palo fierro (Chloroleucon mangense var. leucospermum), palo zorrillo (Senna atomaria) y chilicote (Erythrina sp.). Otros elementos, en diversas combinaciones son el pochote o ceiba (Ceiba acuminata, C. aesculifolia), amapa rosa (Tabebuia impetiginosa), rosa amarilla (Cochlospermum vitifolium), cuajilote (Pseudobombax palmeri), Wimmeria mexicana y cactáceas como cholla arborescente (Opuntia thurberi), nopal (O. wilcoxii), etcho (Pachycereus pecten-aboriginum), Stenocereus montanus y $S$. thurberi.

Hacia su límite superior de elevación, hasta a $2160 \mathrm{~m}$ su fisonomía es intermedia con la del matorral subtropical, con Bursera multijuga, B. palmeri e Ipomoea murucoides, acompañados por Erythrina flabelliformis, Aralia humilis y Melochia tomentosa, mientras que hacia las partes bajas y en sitios protegidos como orilla de arroyos y en cañadas el bosque asume formas más altas y densas y presenta algunos de los elementos del bosque tropical subcaducifolio como son Ficus, Bursera y Brosimum, con Eugenia y Combretum en el estrato bajo. Otros elementos son Annona sp., Guarea glabra, Tabebuia impetiginosa, Enterolobium cyclocarpum y Lonchocarpus sp.

\section{2. Bosque tropical subcaducifolio}

Cubriendo apenas $1.6 \%$ de la superficie total, este tipo de vegetación se ubica entre los 350 y $1200 \mathrm{~m}$ de elevación, en manchones discontinuos en laderas protegidas de la insolación y en cañadas. Clima cálido subhúmedo, lluvias en verano, temperaturas medias anuales entre 23 y $26^{\circ} \mathrm{C}$, libre de heladas y precipitación de 900 a $1300 \mathrm{~mm}$, con 5 a 6 meses secos.

Son bosques densos en las que la mitad o más de sus componentes permanecen con follaje durante todo el año. Presentan dos estratos arbóreos, de 15 a $30 \mathrm{~m}$ de alto. Entre sus elementos característicos están los chalates o tescalamas/es (Ficus spp.), pochote (Ceiba acuminata), palo mulato (Bursera simaruba), cedro (Cedrela odorata), tapaco (Stemmadenia tomentosa), apomo/capomo/ramón (Brosimum alicastrum) y guamúchil (Pithecellobium dulce). En un estrato más bajo destacan Cochlospermum vitifolium, Agonandra racemosa, Eugenia sp., cepillo (Combretum farinosum), Cupania dentata, guamúchil (Pithecellobium dulce), arellane/arrellán (Psidium sartorianum), haba (Hura polyandra), zapote blanco (Casimiroa edulis), ortiguilla (Urera baccifera), cumbro (Celtis iguanaea), tatachinole (Tournefortia hartwegiana) y Thouinidium decandrum (González Elizondo et al., 2007). 
Entre los elementos del bosque tropical subcaducifolio y caducifolio para Sonora Van Devender et al. (2010) mencionan al palo barril (Cochlospermum vitifolium), palo joso (Conzattia multiflora), sahuira (Stenocereus montanus) y tampiserán (Platymiscium trifoliatum), los cuales alcanzan su límite boreal en el sur de Sonora, así como al aguacate de dos hojas (Dendropanax arboreus) que en Sonora sólo se encuentra en el tropical subcaducifolio.

\section{3. Matorral subtropical}

Ocupa al menos un 3.6\% de la superficie al occidente de la SMO, desde los 500 hasta los $2000 \mathrm{~m}$ s.n.m., aunque otras comunidades secundarias que también se conocen con este nombre se localizan desde los $300 \mathrm{~m}$ de elevación. Se presenta en climas cálidos y secos, con temporada seca de 6 a 9 meses. Puede ser de tipo primario, aunque históricamente derivado del bosque tropical caducifolio, o secundario a partir de ese mismo tipo de vegetación. Se trata de matorrales inermes o espinosos, caducifolios, con algunos árboles bajos y muy espaciados.

Con el nombre de "matorral espinoso de piedemonte", Martínez-Yrízar et al. (2010) lo describen para Sonora ocupando una franja entre el bosque tropical caducifolio y los bosques templados de encino, con una parte hacia el norte limitando con matorrales xerófilos. Entre sus componentes citan a Ipomoea arborescens, cazahuates/ tropillos (Ipomoea spp.), Bursera spp., palo dulce/vara dulce (Eysenhardtia polystachya), tepame (Acacia pennatula), acebuche (Forestiera sp.) y colorín/chilicote (Erythrina flabelliformis). Van Devender et al. (2012b) consideran al "foothills thornscrub" como un tipo de vegetación bien definido que evolucionó en el noroeste de México, muy bien representado en Sonora, donde es importante, ampliamente distribuido y subestimado.

En Sonora alcanza los $30^{\circ} 30^{\prime} \mathrm{N}$ en la cuenca del río Bavispe (Van Devender et al., 2010). Se presenta en laderas bajas y piedemonte de las sierras. Son comunes las asociaciones de palo blanco/palo santo (Ipomoea arborescens), tabachín (Caesalpinia pulcherrima) y ocotillo macho (Fouquieria macdougalii), así como otras de Ipomoea arborescens, tepeguage (Lysiloma watsonii), Acacia cochliacantha con mezquite (Prosopis velutina), papelío (Jatropha cordata) y Fouquieria macdougalii.

Un matorral subtropical de origen secundario por perturbación en bosque tropical se presenta desde el sur de Sonora hasta Zacatecas. Se compone de diversos arbustos y árboles caducifolios y espinosos entre los que destaca el güinolo (Acacia cochliacantha) y cactos columnares como la pitahaya (Stenocereus thurberi), presentando ligas con los matorrales subtropicales secundarios de más al sur, particularmente con el "monte vinolo" de Durango y Sinaloa (González Elizondo et al., 2007) y con los de Nueva Galicia (Rzedowski y McVaugh, 1966). 
En Durango el matorral subtropical cruza la sierra a través de la quebrada del Mezquital y forma ambientes intermedios entre el bosque tropical caducifolio y los matorrales xerófilos. Los árboles son inermes como palo bobo (Ipomoea murucoides), papelillos y copalillos (Bursera spp.) y vara dulce (Eysenhardtia polystachya), o espinosos como Acacia pennatula y palo verde (Cercidium praecox).

Hacia el interior del estado, en partes bajas adyacentes al río Mezquital, los componentes del bosque tropical caducifolio se van diluyendo entre los elementos del matorral xerófilo, formando asociaciones intermedias entre ambos tipos de vegetación, en donde Ipomoea murucoides (palo bobo), Acacia pennatula (huizache tepame) y especies de Bursera (B. fagaroides, B. excelsa, B. multijuga o B. palmeri), se presentan con elementos del matorral xerófilo como Acacia neovernicosa, Opuntia sp. y Fouquieria splendens.

\section{4. Matorral de Dodonaea}

Representa una variante de matorral subtropical secundario dominado por jarilla (Dodonaea viscosa) y en la que faltan la mayor parte de los elementos de dicho matorral. Se distribuye en manchones entre $10 \mathrm{~s} 1500$ y $2050 \mathrm{~m}$ de altitud, fragmentando bosques de encino y bosque tropical caducifolio. Su distribución discontinua hace difícil cuantificar la superficie que ocupa.

Dodonaea viscosa es una agresiva especie leñosa que está convirtiéndose en elemento dominante en sitios perturbados tanto en Durango (González Elizondo et al., 2007) como en el norte de Jalisco (Luquín et al., 2004). Se presenta en áreas de ecotono entre los bosques bajos de encino y los matorrales subtropicales o los matorrales xerófilos, entre los 1700 y 2100 m s.n.m., con frecuencia sobre suelos volcánicos de color pálido, intemperizados. Los encinares bajos están siendo reemplazados por densos matorrales de Dodonaea, a veces acompañada de Dasylirion durangense Trel., otra especie que también es favorecida por fuego.

\section{COMUNIDADES DE DISTRIBUCIÓN TRANSVERSAL}

Son comunidades representadas en todos los ecosistemas, a través de la mayor parte del gradiente de elevación.

\section{1. Bosques de galería}

Se encuentran desde las partes más bajas hasta a más de $2900 \mathrm{~m}$ de altitud, en todos los tipos de clima. Los componen los árboles que se desarrollan a lo largo de corrientes de agua y con frecuencia están constituidos por los mismos elementos del 
bosque circundante, pero en mayor densidad y mayor talla, favorecidos por la humedad (Rzedowski, 1978) y las especies montanas a menudo alcanzan sus límites inferiores de distribución a través de los hábitas riparios (Van Devender, com. pers.). Las comunidades riparias concentran agua, nutrientes y semillas de grandes áreas y por ser comunidades lineares, transversales sobre los otros tipos de vegetación, varían ampliamente en composición y estructura dependiendo del ecosistema donde se encuentren.

En la zona templada y semifría las cañadas riparias presentan ailes o alisos (Alnus acuminata y A. jorullensis), cedros/sabinos (Cupressus arizonica y C. lusitanica) y alisos/sicomoros (Platanus spp.) en sitios mésicos, así como cahuites y pinabetes (Abies durangensis y Pseudotsuga menziesii) en los húmedos y más fríos. Otros componentes de bosque de galería en la sierra son Pinus strobiformis, Quercus sideroxyla y $Q$. rugosa. Entre los elementos arbustivos y árboles bajos destacan los sauces (Salix spp.), capulín (Prunus serotina), fresno (Fraxinus uhdei), Garrya laurifolia, G. ovata, Cornus disciflora y C. excelsa, entre otros.

Para Sonora, de la vertiente occidental de la sierra se registran bosques ribereños con álamos (Populus sp.), sauces (Salix bonplandiana, S. gooddingii), alisos (Platanus wrightii), fresnos (Fraxinus velutina) y nogales (Juglans major) (Van Devender et al., 2010). Asociaciones similares se encuentran en Chihuahua, acompañadas de Cupressus arizonica en algunos sitios y C. lusitanica en otros. Más abajo, a 1200 m, en cañadas rodeadas de bosque bajo abierto, se presentan Quercus spp., Juniperus blancoi var. mucronata, Platanus wrightii y Cupressus sp.

A elevaciones medias (1400-1550 m) en el este de Sonora se encuentran Alnus oblongifolia, Cupressus lusitanica, Ilex tolucana, Juniperus blancoi mucronata y Prunus gentryi. En los cañones de la Sierra Madre Occidental cerca de Yécora hay bosques con alamillo (Alnus oblongifolia), aliso (Platanus wrightii), capulín arroyero (Prunus gentryi), fresno (Fraxinus velutina) y sabinos (Cupressus arizonica, Juniperus blancoi var. mucronata). A menores elevaciones, a orillas de arroyos se localizan bosques de huérigos (Populus monticola), morera cimarrona (Morus microphylla) y sauces (Salix spp.) (Van Devender, 2008).

En Chihuahua, entre los 2000 y $2200 \mathrm{~m}$ se encuentran asociaciones con Pinus strobiformis, Cupressus lusitanica, Quercus rugosa, Q. toumeyi e Ilex rubra.

Dos alisos o sicomoros destacan en el norte del área: capulín arroyero (Platanus gentryi), endémico del este de Sonora, SW de Chihuahua y norte de Sinaloa, hasta los $1000 \mathrm{~m}$ en BG en bosques de pino, y aliso ( $P$. wrightii), que es común en Chihuahua, hasta los $2000 \mathrm{~m}$.

Para zonas más bajas, con elementos termófilos, Martin et al. (1998) describen bosques ribereños tropicales con sauces (Salix spp.) asociados con guásima 
(Guazuma ulmifolia) y sabino (Taxodium distichum var. mexicanum. Los sabinos o ahuehuetes se distribuyen en las partes bajas, hasta los $900 \mathrm{~m}$ de elevación, desde Jalisco y Nayarit hasta Sonora. Otros elementos en las cañadas de bosque tropical son los tescalames o nacapules (Ficus spp.) y la uvalama (Vitex mollis).

\section{2. Pastizales inducidos}

Se encuentran en diversos climas, desde los cálidos semisecos y cálidos subhúmedos en las partes más bajas hasta los templados subhúmedos y semifríos subhúmedos, desde los 300 hasta los $3100 \mathrm{~m}$ de altitud.

Son comunidades herbáceas, principalmente de gramíneas, cuya persistencia está determinada por la intervención del hombre o de sus animales domésticos. Entre las especies indicadoras de disturbio están los zacates tres barbas (Aristida spp.), pata de gallo (Cynodon dactylon), zacate Natal/rosado (Melinis repens) y Sorghum halepense. En las zonas de menor elevación se cultiva para forraje el zacate buffel (Pennisetum ciliare) y, en menor proporción, el zacate Rhodes (Chloris gayana) y el pasto Guinea (Megathyrsus maximus), mientras que en claros abiertos en bosque templado ocasionalmente se siembran Eleusine multiflora y Lolium multiflorum (Herrera Arrieta y Cortés Ortiz, 2009). Especies invasivas que representan una amenaza para la diversidad son Melinis repens y Pennisetum ciliare (Van Devender et al., 2005; González-Elizondo et al., 2009b), en el primer caso para bosque bajo abierto, bosque de encino y pastizal, y en el segundo para matorral xerófilo, matorral subtropical y bosque tropical. El zacate africano (Eragrostis lehmanniana) se ha convertido en una invasora en pastizales en el piedemonte oriental de la SMO en Chihuahua.

Los pastizales inducidos en áreas previamente ocupadas por bosques de pino o por bosques mixtos se desarrollan en áreas que han sido desmontadas para uso agrícola y posteriormente abandonadas o en áreas desmontadas con el fin de propiciar el crecimiento de pastos para ganado, a las que se acostumbra quemar periódicamente (González Elizondo et al., 2007). En algunos lugares ocupados por pastizal inducido la vegetación original ha sido totalmente eliminada, pero en otros se conservan aún elementos relictuales del bosque.

\section{ESTADO ACTUAL DE LA VEGETACIÓN}

Gran parte del área forestal de la vertiente oriental y la gran meseta de la SMO son comunidades de dosel abierto en función de la relativamente escasa humedad 
ambiental y muchas de las áreas de bosque templado se han tornado más abiertas en las tres últimas décadas. Bajo los estándares de la UNESCO (Anónimo, 1973), Felger et al. (1997) y Brown et al. (1998), entre otros, las comunidades con menos de $40 \%$ de cobertura de dosel no representan bosques propiamente dichos sino lo que en idioma inglés se denomina woodland. En este trabajo se adopta el criterio de la FAO (Anónimo, 2010) en aras de aportar información compatible con el Inventario Nacional Forestal, donde se consideran como bosques a comunidades de árboles de al menos $5 \mathrm{~m}$ de alto, ya sean densas o abiertas.

Los bosques templados y fríos de la SMO representan un recurso forestal muy importante tanto en términos de extracción de madera como de producción de servicios ambientales. Actualmente estas comunidades están sujetas a una acelerada deforestación, fragmentación de hábitats y reducción en la densidad de los bosques, que en general están haciéndose más abiertos y en diversas áreas están siendo desplazados por matorrales (Casas et al., 1995; González et al., 1993; González-Elizondo et al., 2007; Márquez-Linares y González-Elizondo, 1998; Márquez Linares et al., 2005, 2006).

Las superficies registradas en el Cuadro 2 incluyen las de uso del suelo. La mayor parte de la superficie dedicada a agricultura $\left(17,929 \mathrm{~km}^{2}\right.$ o $7.1 \%$ del total) se localiza en valles intermontanos en el norte-centro de Chihuahua, al igual que la de cuerpos de agua, que en su mayoría corresponden a lagunas en esa región al oriente de la sierra.

\section{CONCLUSIONES}

Las dimensiones de la SMO, con un intervalo de latitud de $10^{\circ}$ entre sus extremos norte y sur; su complejo relieve con elevaciones desde 300 a $3340 \mathrm{~m}$; su ubicación con la parte norte lejos del mar y la parte media y sur paralelas y cercanas a la costa Pacífica; y la confluencia de elementos de la región Neártica y la región Neotropical, resultan en una enorme complejidad climática y de ecosistemas.

La SMO alberga $46 \%$ de las especies de pinos de México, $34 \%$ de los encinos y $100 \%$ de los madroños, cifras considerablemente altas tomando en cuenta que la mayor diversidad de pinos y de madroños a nivel mundial, y la segunda en el caso de Quercus, se localiza en México. A pesar de su importancia ambiental, económica y científica, la SMO es todavía una de las regiones más deficientemente conocidas biológica y ecológicamente en México. Diversas comunidades requieren ser estudiadas. Entre ellas está la vegetación de ciénegas que, hasta donde se conoce, albergan una alta proporción de endemismos y tienen gran valor ambiental, pero se encuen- 
tran bajo fuerte amenaza por la desecación de las áreas en donde se desarrollan. Entre los bosques de pino-encino y los bosques mixtos de coníferas existen también comunidades de gran interés.

Conocer y conservar la diversidad biológica y los ecosistemas de la SMO es urgente por diversas razones. La presente síntesis pretende ser un punto de partida para futuros estudios en los que pueda explorarse y darse a conocer a detalle la enorme riqueza de la Sierra Madre Occidental.

\section{AGRADECIMIENTOS}

Al Dr. Tom Van Devender y al Dr. Richard Spellenberg por compartir generosamente su conocimiento sobre la SMO. A la L.I. Laura M. Rojas Piedra y al Ing. Eliodoro Huerta Alatorre por su apoyo para elaboración de los mapas. A la Comisión de Operación y Fomento de Actividades Académicas por los estímulos a la investigación. El trabajo fue desarrollado con apoyo económico del Instituto Politécnico Nacional (proyecto 20110681). Las sugerencias de tres revisores anónimos permitieron mejorar sustancialmente el manuscrito.

\section{LITERATURA CITADA}

Adams, R. P., M. S. González-Elizondo, M. González-Elizondo y E. Slinkman. 2006. DNA fingerprinting and terpenoid analysis of Juniperus blancoi var. huehuentensis (Cupressaceae), a new subalpine variety from Durango, Mexico. Biochem. Syst. Ecol. 34: 205-211.

Anónimo. 1973. International classification and mapping of vegetation. United Nations Educational, Scientific and Cultural Organization. París, Francia. 35 pp.

Anónimo. 1997. Regiones ecológicas de América del Norte. Hacia una perspectiva común. Comisión para la Cooperación Ambiental de América del Norte. Quebec, Canadá. $63 \mathrm{pp}$.

Anónimo. 2001. San Pedro Mezquital. World Wildlife Fund. http://wwf.org.mx/sanpedro mezquital/ (consultado el 24 de marzo 2012).

Anónimo. 2002. Conjunto de datos vectoriales de la carta de uso del suelo y vegetación: escala 1: 250 000. Serie III (continuo nacional). Instituto Nacional de Estadística, Geografía e Informática. Aguascalientes, México.

Anónimo. 2003a. Continuo de elevaciones mexicano escala 1:50 000. Instituto Nacional de Estadística, Geografía e Informática (http://mapserver.inegi.gob.mx/DescargaMDE Web). 
Anónimo. 2003b. Conjunto de datos vectoriales de la carta de Climas escala 1:1 000000. Instituto Nacional de Estadística y Geografía. Aguascalientes, México.

Anónimo. 2005. Conjunto de datos vectoriales de la carta de uso del suelo y vegetación escala 1: 250 000. Serie IV (continuo nacional). Instituto Nacional de Estadística y Geografía. Aguascalientes, México.

Anónimo. 2007. Ecorregiones terrestres de México. Escala 1: 1000 000. Instituto Nacional de Estadística, Geografía e Informática; Comisión Nacional para el Conocimiento y Uso de la Biodiversidad e Instituto Nacional de Ecología. México, D.F, México.

Anónimo. 2010. Evaluación de los recursos forestales mundiales. Organización de las Naciones Unidas para la Agricultura y la Alimentación. Roma, Italia. http://www. fao.org/forestry/fra/62219/es/ (consultado el 31 de marzo 2012).

Aragón-Piña, E. E., A. Garza-Herrera, M. Socorro González-Elizondo e I. Luna-Vega. 2010. Composición y estructura de las comunidades vegetales del rancho El Durangueño, en la Sierra Madre Occidental, Durango, México. Rev. Mex. Biodiv. 81: 771-787.

Arriaga, L. y L. Gómez. 2004. El cambio climático y la vegetación en México. In: Martínez, J. y A. Fernández Bremauntz. (comps.). Cambio climático: Una visión desde México. Secretaría de Medio Ambiente y Recursos Naturales-Instituto Nacional de Ecología. México, D.F., México. pp. 255-265.

Arriaga C., L., J. M. Espinoza-Rodríguez, C. Aguilar-Zúñiga, E. Martínez-Romero, L. Gómez-Mendoza y E. Loa Loza. (coords.). 2000. Regiones terrestres prioritarias de México. Comisión Nacional para el Conocimiento y Uso de la Biodiversidad. México, D.F., México. 609 pp.

Axelrod, D. I. 1958. Evolution of the Madro-Tertiary geoflora. Bot. Rev. 24: 435-509.

Axelrod, D. I. 1975. Evolution and biogeography of Madrean-Tethyan sclerophyll vegetation. Ann. Mo. Bot. Gard. 62: 280-334.

Baab, K., M. Blanco y Correa, R. E. González Flores, J. A. Navarrete Carrillo, O. Téllez Valdés y R. Vega Aviña. 2010. Serranías de Nayarit. El bosque mesófilo de montaña en México: amenazas y oportunidades para su conservación y manejo sostenible. Comisión Nacional para el Conocimiento y Uso de la Biodiversidad. México, D.F., México. 197 pp.

Brown, D. E., F. Reichenbacher y S. E. Franson. 1995. A classification system and map of the biotic communities of North America. In: DeBano, L. F., P. F. Ffolliott, A. Ortega Rubio, G. J. Gottfried, R. H. Hamre y C. B. Edminster. (coords.). 1995. Biodiversity and management of the Madrean archipelago: The sky islands of southwestern United States and northwestern Mexico. United States Department of Agriculture Forest Service, General Technical Report RM 264: 109-125.

Brown, D. E., F. Reichenbacher y S. E. Franson. 1998. A classification of North American biotic communities. The University of Utah Press. Salt Lake City, USA. 141 pp. + mapa.

Búrquez M., J. A. 1998. Diversidad vegetal en un gradiente en la Sierra Madre Occidental: flora y vegetación de la región de San Javier y Yécora, Sonora. Sistema Nacional de Información sobre Biodiversidad-Comisión Nacional para el Conocimiento y Uso de la Biodiversidad. Informe final del proyecto H122. México, D.F., México. 
Búrquez M., A., A. Martínez Y. y P. S. Martin. 1992. From the high Sierra Madre to the coast: changes in vegetation along highway 16, Maycoba-Hermosillo. In: Clark, K. F., J. Roldán Q. y R. H. Schmidt (eds.). Geology and mineral resources of the northern Sierra Madre Occidental, Mexico. Guidebook. El Paso Geological Survey Publication 24. El Paso, Texas, USA. pp. 239-252.

Bye, R. 1995. Prominence of the Sierra Madre Occidental in the biological diversity of Mexico. In: DeBano, L. F., P. F. Ffolliott, A. Ortega Rubio, G. J. Gottfried, R. H. Hamre y C. B. Edminster. (coord.). Biodiversity and management of the Madrean archipelago: The sky islands of Southwestern United States and Northwestern Mexico. United States Department of Agriculture Forest Service, General Technical Report RM 264: 19-27.

Carrillo-Reyes, P., R. Vega Aviña y R. Ramírez-Delgadillo. 2003. Agave rzedowskiana, a new species in subgenus Littaea (Agavaceae) from western Mexico. Brittonia 55(3): 240-244.

Carrillo-Reyes, P. 2008. A new species of Perityle (Asteraceae, Perityleae) from Western Mexico. Syst. Bot. 33(2): 459-461.

Casas S., R., S. González E. y J. A. Tena F. 1995. Estructura y tendencias sucesionales en bosques de clima templado semi-seco en Durango, Mexico. Madroño 42(4): 501-515.

Challenger, A. y J. Soberón. 2008. Los ecosistemas terrestres. In: Sarukhán, J. (coord. gral.). Capital natural de México: Conocimiento actual de la biodiversidad. Vol. I. Comisión Nacional para el Conocimiento y Uso de la Biodiversidad. México, D.F., México. pp. 87-108.

Cowan, P. D. y D. D. Ackerly. 2009. Post-fire regeneration strategies and flammability traits of California chaparral shrubs. Int. J. Wildland Fire 19(7): 984-989.

Cortés Montaño, C. 2011. The treasure of the Sierra Madre: Ecology of old-growth forests in Chihuahua, Mexico. Tesis de doctorado. School of Forestry, Northern Arizona University. Flagstaff, Arizona, USA. 139 pp.

Cortés Montaño, C. 2012. Los bosques antiguos del ejido Cinco de Mayo en Chihuahua. Patrimonio natural de México. Folleto de divulgación. Programa IGERT, Universidad del Norte de Arizona y Dirección del Legado para la Sostenibilidad del Instituto Tecnológico de Monterrey. $18 \mathrm{pp}$.

DeBano, L. F., P. F. Ffolliott, A. Ortega Rubio, G. J. Gottfried, H. R. Hamre y C. B. Edminster. (coord.). 1995. Biodiversity and management of the Madrean archipelago: The sky islands of southwestern United States and northwestern Mexico. United States Department of Agriculture Forest Service, General Technical Report RM GTR 264.

Descroix, L., J. L. González Barrios y J. Estrada Ávalos (eds.). 2004. La Sierra Madre Occidental, una fuente de agua amenazada. Instituto Nacional de Investigaciones Forestales, Agrícolas y Pecuarias-Institut de Recherche pour le Développement. Gómez Palacio, Durango, México. 300 pp.

Enríquez, E. D., S. D. Koch y M. S. González-Elizondo. 2003. Flora y Vegetación de la Sierra de Órganos, municipio de Sombrerete, Zacatecas. México. Acta Bot. Mex. 64: 45-89.

Escalante, T., G. Rodríguez y J. J. Morrone. 2005. Las provincias biogeográficas del Componente Mexicano de Montaña desde la perspectiva de los mamíferos continentales. Rev. Mex. Biodiv. 76(2): 207-252. 
Espinosa, D., S. Ocegueda, C. Aguilar, Ó. Flores, J. Llorente-Bousquets, B. Vázquez. 2008. El conocimiento biogeográfico de las especies y su regionalización natural. In: Sarukhán, J. (coord. gral.). Capital natural de México. Vol. I: Conocimiento actual de la biodiversidad. Comisión Nacional para el conocimiento y Uso de la Biodiversidad. México, D.F., México. pp. 33-65.

Estrada-Castillón, A. E., E. Jurado, J. J. Návar, J. Jiménez-Pérez y F. Garza-Ocañas. 2003. Plant associations of Cumbres de Majalca National Park, Chihuahua, Mexico. The Southw. Nat. 48(2): 177-187.

Estrada-C., A. E., R. Spellenberg y T. Lebgue. 1997. Flora vascular de la Laguna de Babícora, Chihuahua, México. Sida 17: 809-827.

Estrada C., A. E., J. Á. Villarreal Q. y M. González E. 2004. A new species of Dalea sect. Parosela (Fabaceae: Amorpheae) from Mexico. Brittonia 56: 67-71.

Felger, R. S. y M. F. Wilson. 1995. Northern Sierra Madre Occidental and its Apachian outliers: A neglected center of biodiversity. In: DeBano, L. F., P. F. Ffolliott, A. Ortega Rubio, G. J. Gottfried, R. H. Hamre y C. B. Edminster. (coords.). 1995. Biodiversity and management of the Madrean archipelago: The sky islands of southwestern United States and northwestern Mexico. United States Department of Agriculture Forest Service, General Technical Report RM 264: 36-59.

Felger, R. S. y M. B. Johnson. 1995. Trees of the Northern Sierra Madre. Occidental and Sky Islands of Southwestern North America. In: DeBano, L. F., P. F. Ffolliott, A. Ortega Rubio, G. J. Gottfried, R. H. Hamre y C. B. Edminster. (coord.) 1995. Biodiversity and management of the Madrean archipelago: The sky islands of southwestern United States and northwestern Mexico. United States Department of Agriculture Forest Service, General Technical Report RM 264: 71-77.

Felger, R., G. Nabhan y R. Bye. 1997. The Apachian/Madrean region of southwestern North America and U.S.A. In: Davis, S. D., V. H. Heywood, O. Herrera-McBryde, J. VillaLobos y A. C. Hamilton (eds.). Centres for plant diversity: a guide and strategy for their conservation.Vol. III. The Americas. The World Wide Fund for Nature \& International Union for the Conservation of Nature-The World Conservation Union. Cambridge, UK. pp. 172-180.

Felger, R. S., M. B. Johnson y M. F. Wilson. 2001. The trees of Sonora, Mexico. Oxford University Press. New York, USA. 391 pp.

Ferrari, L., M. Valencia-Moreno, S. Bryan. 2005. Magmatismo y tectónica en la Sierra Madre Occidental y su relación con la evolución de la margen occidental de Norteamérica. Bol. Soc. Geol. Mex. 57(3): 343-378.

Ferrusquía-Villafranca, I. 1993. Geology of Mexico: A synopsis. In: Ramamoorthy, T. P., R. Bye, A. Lot y J. Fa (eds.). Biological diversity of Mexico: Origins and distribution. Oxford University Press. New York, USA. pp. 3-107.

Finot, V. L., P. M. Peterson, R. J. Soreng y F. O. Zuloaga. 2004. A revision of Trisetum, Peyritschia and Sphenopholis (Poaceae: Pooideae: Aveninae) in Mexico and Central America. Ann. Mo. Bot. Gard. 91: 1-30.

Fisher, J. T., P. A. Glass y J. T. Harrington. 1995. Temperate pines of northern Mexico: their use, abuse and regeneration. In: DeBano, L. F., P. F. Ffolliott, A. Ortega Rubio, G. J. Gottfried, R. H. Hamre y C. B. Edminster. (coords.). Biodiversity and management 
of the Madrean archipelago: The sky islands of southwestern United States and northwestern Mexico. United States Department of Agriculture Forest Service, General Technical Report RM 264: 165-173.

Fulé, P. Z. y W. W. Covington. 1997. Fire regimes and forest structure in the Sierra Madre Occidental, Durango, México. Acta Bot. Mex. 41: 43-79.

Fulé, P. Z., M. A. Ramos-Gómez, C. Cortés Montaño y A. M. Miller. 2011. Fire regime in a Mexican forest under indigenous resource management. Ecol. Appl. 21(3): 764-775.

Fulé, P. Z., L. L. Yocom, C. Cortés Montaño, D. A. Falk, J. Cerano Paredes y J. Villanueva Díaz. (en prensa). Testing a pyroclimatic hypothesis on the México-U.S. border. Ecology.

García, E. 1998. Climas (Clasificación de Köppen, modificada por García) Escala 1:1 000000. Comisión Nacional para el Conocimiento y Uso de la Biodiversidad. México, D.F., México.

García Arévalo, A. 2008. Vegetación y flora de un bosque relictual de Picea chihuahuana Martínez del norte de México. Polibotánica 25: 45-68.

García Arévalo, A. y M. S. González-Elizondo. 2003. Pináceas de Durango. Comisión Nacional Forestal e Instituto de Ecología, A.C. 2a. ed. México, D.F., México. 187 pp.

García Arévalo, A., J. J. Mendoza Contreras y J. Nocedal. 2004. Asociaciones vegetales de los bosques del municipio de Guanaceví, Durango. Madera y Bosques 10: 21-34.

Gentry, H. S. 1942. Rio Mayo plants. A study of the flora and vegetation of the Valley of the Rio Mayo, Sonora. Carnegie Institution of Washington Publication 527. Washington, D.C., USA. 328 pp.

Goldberg, D. E. 1982. The distribution of evergreen and deciduous trees relative to soil type: an example from the Sierra Madre, Mexico, and a general model. Ecology 63: 942-951.

González-Elizondo, M., E. Jurado, M. S. González-Elizondo, J. Villanueva, J. Návar, O. Aguirre y J. Jiménez. 2005. Tree-rings and climate relationships for Douglasfir chronologies from the Sierra Madre Occidental, Mexico: a 1681-2001 rain reconstruction. Forest Ecol. Manag. 213(1): 39-53.

González Elizondo, M., R. Galván Villanueva, I. L. López Enriquez, L. Reséndiz Rojas y M. S. González Elizondo. 2009a. Agaves -magueyes, lechuguillas y noas- del Estado de Durango y sus alrededores. Centro Interdisciplinario de Investigación para el Desarrollo Integral Regional Unidad Durango del Instituto Politécnico NacionalComisión Nacional para el Conocimiento y Uso de la Biodiversidad. Durango, México. 163 pp.

González-Elizondo, M., M. S. González-Elizondo, L. Ruacho González y M. Molina Olvera. 2011. Pinus maximartinezii Rzed., primer registro para Durango, segunda localidad para la especie. Acta Bot. Mex. 96: 33-48.

González-Elizondo, M. S. 1997. Upper Mezquital River region, Sierra Madre Occidental, Mexico, In: Davis, S. D., V. H. Heywood, O. Herrera-McBryde, J. Villa-Lobos y A. C. Hamilton (eds.). Centres for plant diversity: a guide and strategy for their conservation. Vol. III: The Americas. The World Wide Fund for Nature \& International Union for the Conservation of Nature - The World Conservation Union. Cambridge, UK. pp. $157-160$. 
González-Elizondo, M. S. y M. González E. 1992a. Una nueva especie de Arbutus (EricaceaeArbuteae) de la Sierra Madre Occidental, Mexico. Acta Bot. Mex. 17: 7-12.

González-Elizondo, M. S. y M. González-Elizondo. 1992b. El género Arbutus (Ericaceae) en la Sierra Madre Occidental. Consideraciones sobre su taxonomía y distribución. Bol. Inst. Bot. Univ. Guadalajara 1(2): 39-41.

González-Elizondo, S., M. González-Elizondo y A. Cortés-Ortiz. 1993. Vegetación de la Reserva de la Biosfera La Michilía, Durango, Mex. Acta Bot. Mex. 22: 1-104 + mapa.

González-Elizondo, M. S., I. L. López Enriquez y W. L. Wagner. 2002. Megacorax gracielanus (Onagraceae), a new genus and species from Durango, Mexico. Novon 12: 360-365.

González Elizondo, M. S., M. González Elizondo y M. A. Márquez Linares. 2007. Vegetación y ecorregiones de Durango. Plaza y Valdés Editores-Instituto Politécnico Nacional. México, D.F., México. 219 pp.

González Elizondo, M. S., M. González Elizondo, J. A. Tena Flores, I. L. López Enríquez y J. R. Bacon. 2009b. Durango: Detection of invasive alien plants. In: Van Devender, T. R., F. J. Espinosa-García, B. L. Harper-Lore y T. Hubbard (eds.). Invasive plants on the Move: Controlling them in North America. Based on presentations at Weeds accross borders 2006 Conference. Arizona-Sonora Desert Museum. Tucson, Arizona, USA. pp. 137-155.

González-Elizondo, M. S., M. González-Elizondo y P. D. Sørensen. 2012a. Arbutus bicolor (Ericaceae), a new species from Mexico. Acta Bot. Mex. 20: 55-72.

González-Elizondo, M. S., M. González-Elizondo, L. Ruacho González, I. L. López Enríquez, F. I. Retana Rentería y J. A. Tena Flores. 2012b. (en prensa). Ecosystems and diversity of the Sierra Madre Occidental. In: Gottfried, G. J., P. F. Ffolliott, B. S. Gebow y L. G. Eskew. (comps.). Merging science and management in a rapidly changing world: biodiversity and management of the Madrean Archipelago III. Proceedings RMRS-P-67. Fort Collins, CO: U.S. Department of Agriculture, Forest Service, Rocky Mountain Research Station. Fort Collins, Colorado, USA.

Gordon, A. G. 1968. Ecology of Picea chihuahuana Martínez. Ecology 49: 880896.

Halffter, G. 1976. Distribución de los insectos en la Zona de Transición Mexicana: Relaciones con la entomofauna de Norteamérica. Folia Entomol. Mex. 35: 1-64.

Herrera-Arrieta, Y. y P. M. Peterson. 2007. Muhlenbergia (Poaceae) de Chihuahua, México. Instituto Politécnico Nacional-Smithsonian Institution-Comisión Nacional para el Conocimiento y Uso de la Biodiversidad. México, D.F., México. 109 pp.

Herrera Arrieta, A. y A. Cortés Ortiz. 2009. Diversidad de las gramíneas de Durango, México. Polibotánica 28: 49-68.

Herrera-Arrieta, Y., P. M. Peterson y A. Cortés O. 2009. Gramíneas de Zacatecas, México. Sida, Bot. Misc. 32: 1-239.

Jaramillo-Correa, J. P., J. Beaulieu, F. T. Ledig y J. Bousqueter. 2006. Decoupled mitochondrial and chloroplast DNA population structure reveals Holocene collapse and population isolation in a threatened Mexican-endemic conifer. Mol. Ecol. 15(10): 2787-2800.

Koleff, P., J. Soberon y A. Smith. 2004. Madrean Pine-Oak Woodlands. In: Mittermeier, R. A., P. R. Gil, M. Hoffman, J. Pilgrim, T. Brooks, C. G. Mittermeier, J. Lamoreux y 
G. A. B. da Fonseca (eds.). Hotspots revisited: Earth's biologically richest and most threatened terrestrial ecoregions. CEMEX - Agrupación Sierra Madre, Mexico City, México. pp. 205-217.

Laferriére, J. E. 1994. Vegetation and flora of the Mountain Pima Village of Nabogame, Chihuahua, México. Phytologia 77: 102-140.

Lebgue Keleng, T. 2002. Flora de las Barrancas del Cobre (Región Prioritaria 45). Sistema Nacional de Información sobre Biodiversidad-Comisión Nacional para el Conocimiento y Uso de la Biodiversidad. Informe final del proyecto R102. México, D.F., México.

Lebgue Keleng, T. 2005. Análisis de las comunidades vegetales de las Barrancas del Cobre, municipios de Batopilas y Urique, Chihuahua, usando un Sistema de Información Geográfica. Tesis doctoral. Facultad de Zootecnia, Universidad Autónoma de Chihuahua. Chihuahua, Chih., México. 109 pp.

LeSueur, H. 1945. The ecology of the vegetation of Chihuahua, Mexico, north of parallel twenty-eight. University of Texas Publication 4521: 1-92.

López-Ferrari, A. R. y A. Espejo-Serna. 2007. Tillandsia borealis (Bromeliaceae), una nueva especie del norte de México. Bol. Soc. Bot. Méx. 80: 63-71.

Lumholtz, C. 1902. Unknown Mexico. Explorations in the Sierra Madre and other 271 regions, 1890-1898. Vol. 1. Dover Publications. New York, USA. 316 pp.

Luquín S., H., G. Nieves H. y J. M. Ayala R. 2004. Vegetación del norte de Jalisco. In: Vázquez-García, J. A., M. de J. Cházaro B., G. Nieves H., Y. L. Vargas-Rodríguez, M. Vázquez G. y A. Flores M. (eds.). Flora del norte de Jalisco y etnobotánica huichola. Serie Fronteras de Biodiversidad 1. Centro Universitario de Ciencias Biológicas y Agropecuarias y Centro Universitario de Ciencias Sociales y Humanidades de la Universidad de Guadalajara. Guadalajara, Jalisco, México. pp. 77-83.

Márquez-Linares, M. A. y M. S. González-Elizondo. 1998. Composición y estructura del estrato arbóreo de un bosque de pino encino en Durango, México. Agrociencia 32(4): 413-419.

Márquez Linares, M. A., M. S. González Elizondo y R. Álvarez Zagoya. 1999. Componentes de la diversidad arbórea en bosques de pino encino de Durango, México. Madera y Bosques 5(2): 67-78.

Márquez Linares, M. A., E. Jurado y C. López González. 2005. Efecto del fuego en el establecimiento de Arctostaphylos pungens HBK. en ecosistemas templados semihúmedos de Durango, México. Madera y Bosques 11(2): 35-48.

Márquez Linares, M. A., E. Jurado y S. González Elizondo. 2006. Algunos aspectos de la biología de la manzanita (Arctostaphylos pungens HBK.) y su papel en el desplazamiento de bosques templados por chaparrales. Ciencia UANL 9(1): 57-64.

Martin, P. S., D. Yetman, M. Fishbein, P. Jenkins, T. R. Van Devender y R. K. Wilson. 1998. Gentry's Río Mayo plants: The tropical deciduous forest and environs of Northwest Mexico. The University of Arizona Press. Tucson, Arizona, USA. 558 pp.

Martínez-Yrízar, A. R. S. Felger y A. Búrquez. 2010. Los ecosistemas de Sonora: un diverso capital natural. In: Molina Freaner, F. y T. Van Devender (eds.). Diversidad biológica de Sonora. Universidad Nacional Autónoma de México/Comisión Nacional para el Conocimiento y Uso de la Biodiversidad. México, D.F., México. pp. 129-156. 
Mastretta-Yanes, A., A. Wegier, A. Vázquez-Lobo y D. Piñero. 2011. Distinctiveness, rarity and conservation in a subtropical highland conifer. Conserv. Genet. 13(1): 211-222. DOI 10.1007/s10592-011-0277-y.

Mathiasen, R. L., M. S. González Elizondo, M. González Elizondo, B. E. Howell, I. L. López Enriquez, J. Scott y J. A. Tena Flores. 2008. Distribution of dwarf mistletoes (Arceuthobium spp., Viscaceae) in Durango, Mexico. Madroño 55(2): 161-169.

Mayfield, M. H. y V. W. Steinmann. 2010. Euphorbia spellenbergiana (Euphorbiaceae), a new species from Mexico. Acta Bot. Mex. 90: 43-50.

Maysilles, J. H. 1959. Floral relationships of the pine forests of Western Durango, Mexico. Tesis doctoral. University of Michigan. Ann Arbor, USA. 165 pp.

McDonald, J. A., J. Martínez y G. L. Nesom. 2011. Alpine flora of Cerro Mohinora, Chihuahua, Mexico. J. Bot. Res. Inst. Texas 5(2): 701-705.

Metcalfe, S. E., S. L. O'Hara, M. Caballero y S. J. Davies. 2000. Records of late Pleistocene-Holocene climatic change in Mexico-A review. Quaternary Sci. Rev. 19: 699-721.

Metcalfe, S. E., A. Say, S. Black, R. McCulloch y S. L. O’Hara. 2002. Wet conditions during the last glaciation in the Chihuahuan Desert, Alta Babícora basin, México. Quaternary Res. 57(1): 91-101.

Morán Zenteno, D. J. 2007. El tesoro de la Sierra Madre y el volcanismo terciario del occidente de México. Gaceta UNAM 3960: 9.

Morrone, J. J. 2005. Hacia una síntesis biogeográfica de México. Rev. Mex. Biodiv. 76(2): 207-252.

Morrone, J. J., D. Espinosa Organista y J. Llorente Bousquets. 2002. Mexican biogeographic provinces: Preliminary scheme, general characterizations and synonymies. Acta Zool. Mex. (n.s.) 85: 83-108.

Nabhan, G. 2005. Biocultural diversity and its conservation in the Mother Mountains. In: Gottfried, G. J., B. S. Gebow, L. G. Eskew y C. B. Edminster. (coords.). Biodiversity and management of the Madrean Archipelago II: Connecting mountain islands and desert seas. United States Department of Agriculture Forest Service, General Technical Report RMRS-P-36: 1-631.

Nixon, K. y J. M. Poole. 2003. Revision of the Mexican and Guatemalan species of Platanus (Platanaceae). Lundellia 6: 103-137.

Ortega-Ramírez, J. R., A. Valiente-Banuet, J. Urrutia-Fucugauchi, C. A. Mortera-Gutiérrez y G. Alvarado-Valdez. 1998. Paleoclimatic changes during the Late PleistoceneHolocene in Laguna Babícora, near the Chihuahuan Desert, México. Can. J. Earth Sci. 35(10): 1168-1179.

Ortega-Rosas, C. I., M. C. Peñalba, J. A. López-Sáez y T. R. Van Devender. 2008a. Retrospectiva del bosque de pino y encino de la Sierra Madre Occidental, Sonora, noroeste de México, hace 1000 años. Acta Bot. Mex. 83: 69-92.

Ortega-Rosas, C. I., M. C. Peñalba y J. Guiot. 2008b. Holocene altitudinal shifts in vegetation belts and environmental changes in the Sierra Madre Occidental, Northwestern Mexico, based on modern and fossil pollen data. Rev. Palaeobot. Palynol. 151(1-2): 1-20.

Peterson, P. M., R. Soreng y Y. Herrera-Arrieta. 2006. Poa matri-occidentalis (Poaceae: Pooideae: Poeae: Poinae), a new species from Mexico. Sida 22(2): 905-914. 
Ramírez Noya, D., M. S. González-Elizondo y J. Molina Torres. 2011. Heliopsis suffruticosa (Compositae, Heliantheae), una nueva especie del occidente de Zacatecas. Acta Bot. Mex. 97: 39-47.

Reina-G., A. L. y T. Van Devender. 2005. Floristic comparison of an Arizona Sky Island and the Sierra Madre Occidental in eastern Sonora: the Huachuca Mountains and the Yécora Area. In: Gottfried, G. J., B. S. Gebow, L. G. Eskew y C. B. Edminster. (coords.). Biodiversity and management of the Madrean Archipelago II: Connecting mountain islands and desert seas. United States Department of Agriculture Forest Service, General Technical Report RMRS-P-36: 154-157.

Reina-G., A. L., T. R. Van Devender, W. Trauba y A. Búrquez-M. 1999. Caminos de Yécora. Notes on the vegetation and flora of Yécora, Sonora. In: Vásquez del Castillo, B. D., M. Ortega N. y C. A. Yocupicio-C. (eds.). Memorias del Simposium Internacional Sobre la Utilización y Aprovechamiento de la Flora Silvestre de Zonas Áridas. Hermosillo, Sonora, México. pp. 137-144.

Ruacho González, L. 2011. El elemento alpino en la vegetación de alta montaña de la Sierra Madre Occidental. Tesis de maestría en ciencias (gestión ambiental). Centro Interdisciplinario de Investigación para el Desarrollo Integral Regional, Instituto Politécnico Nacional. Durango, Dgo., México. 83 pp.

Rzedowski, J. 1978. Vegetación de México. Ed. Limusa. México, D.F., México. 432 pp.

Rzedowski, J. 1991. Diversidad y orígenes de la flora fanerogámica de México. Acta Bot. Mex. 14: 3-21.

Rzedowski, J. 1996. Análisis preliminar de la flora vascular de los bosques mesófilos de montaña de México. Acta Bot. Mex. 35: 25-44.

Rzedowski, J. y R. McVaugh. 1966. La vegetación de Nueva Galicia. Contr. Univ. Mich. Herb. 9: 1-123.

Rzedowski, J. y T. Reyna-Trujillo. 1990. Provincias florísticas. Mapa IV.8.3. Atlas Nacional de México. Vol. III. Instituto de Geografía, Universidad Nacional Autónoma de México. México, D.F., México.

Saarela, J. M., P. M. Peterson, M. S. González-Elizondo y D J. Rosen. 2010. Eleocharis cryptica (Cyperaceae), a dwarf new species from Durango, México. Brittonia 62(3): 233-238.

Spellenberg, R. 2007. Dalea analiliana (Fabaceae: Amorpheae), a new species from the northwestern Sierra Madre Occidental, Mexico. Madroño 54: 175-179.

Spellenberg, R. y J. R. Bacon. 1996. Taxonomy and distribution of a natural group of black oaks of Mexico (Quercus subsection Racemiflorae). Syst. Bot. 21: 85-99.

Spellenberg, R., T. Lebgue y R. Corral-Díaz. 1996. A specimen-based, annotated checklist of the vascular plants of Parque Nacional "Cascada de Basaseachi" and adjacent areas, Chihuahua, Mexico. Listados Florísticos de México XIII. , Instituto de Biología, Universidad Nacional Autónoma de México. México, D.F., México. 72 pp.

Spellenberg, R., J. R. Bacon y M. S. González-Elizondo. 1998. Los encinos (QuercusFagaceae) en un transecto sobre la Sierra Madre Occidental. Bol. IBUG 5: 357-387.

Torres-Morales, L., D. F. García-Mendoza, C. López-González y R. Muñiz-Martínez. 2010. Bats of Northwestern Durango, Mexico: Species richness at the interface of two biogeographic regions. The Southwest. Nat. 55(3): 347-362. 
Valiente-Banuet, A., N. Flores-Hernández, M. Verdú y P. Dávila. 1998. The chaparral vegetation in Mexico under non-mediterranean climate: Convergence and MadreanTethyan hypotheses reconsidered. Amer. J. Bot. 85: 1398-1408.

Van Devender, T. R. 2008. La Vegetación y plantas de Sonora. Xoop caacöl 4. http://boletin. apnsac.org/?p=7 (consultado el 8 de enero de 2012).

Van Devender, T. R., A. L. Reina G., M. C. Peñalba G. y C. I. Ortega R. 2003. The Ciénega de Camilo: a threatened habitat in the Sierra Madre Occidental of eastern Sonora, Mexico. Madroño 50(3): 187-195.

Van Devender, T. R., J. R. Reeder, C. G. Reeder y A. L. Reina-G. 2005. Distribution and diversity of grasses in the Yécora region of the Sierra Madre Occidental of eastern Sonora, Mexico. In: Cartron, J.-L. E., G. Ceballos y R. S. Felger (eds.). Biodiversity, ecosystems, and conservation in northern Mexico. Oxford University Press. New York, USA. pp. 107-121.

Van Devender, T. R., R. S. Felger, M. Fishbein, F. E. Molina-Freaner, J. J. SánchezEscalante y A. L. Reina-Guerrero. 2010. Biodiversidad de las plantas vasculares. In: Molina-Freaner, F. E. y T. R. Van Devender (eds.). Diversidad biológica de Sonora. Universidad Nacional Autónoma de México. México, D.F., México. pp. 229-261

Van Devender, T. R., S. Avila-Villegas, M. Emerson, D. Turner, A. D. Flesch y N. S. Deyo. 2012a. (en prensa). Biodiversity in the Madrean Archipelago of Sonora, Mexico. In: Gottfried, G. J., P. F. Ffolliott, B. S. Gebow y L. G. Eskew. (comps.). Merging science and management in a rapidly changing world: biodiversity and management of the Madrean Archipelago III. Proceedings RMRS-P-67. Fort Collins, CO: U.S. Department of Agriculture, Forest Service, Rocky Mountain Research Station. Fort Collins, Colorado, USA.

Van Devender, T. R., G. Yanes-Arvayo, A. L. Reina-Guerrero, M. Valenzuela-Yánez, M. P. Montañez-Armenta y H. Silva-Kurumiya. 2012b. (en prensa). Comparison of the tropical floras of the Sierra la Madera and the Sierra Madre Occidental, Sonora, Mexico. In: Gottfried, G. J., P. F. Ffolliott, B. S. Gebow y L. G. Eskew. (comps.). Merging science and management in a rapidly changing world: biodiversity and management of the Madrean Archipelago III. Proceedings RMRS-P-67. Fort Collins, CO: U.S. Department of Agriculture, Forest Service, Rocky Mountain Research Station. Fort Collins, Colorado, USA.

Vázquez-García, J. A., M. de J. Cházaro B., G. Nieves H., Y. L. Vargas-Rodríguez, M. Vázquez G. y A. Flores M. 2004. Flora del norte de Jalisco y etnobotánica huichola. Serie Fronteras de Biodiversidad 1. Centro Universitario de Ciencias Biológicas y Agropecuarias y Centro Universitario de Ciencias Sociales y Humanidades de la Universidad de Guadalajara. Guadalajara, México. 182 pp.

Villaseñor, J. L. 2010. El bosque húmedo de montaña en México y sus plantas vasculares: catálogo florístico-taxonómico. Comisión Nacional para el Conocimiento y Uso de la Biodiversidad-Universidad Nacional Autónoma de México. México, D.F., México. 40 pp.

Villers-Ruiz, L. y I. Trejo-Vázquez. 1998. Climate change on Mexican forests and natural protected areas. Global Environ. Chang. 8(2): 141-157.

Villers-Ruiz, L. e I. Trejo-Vázquez. 2004. Evaluación de la vulnerabilidad en los ecosistemas forestales. In: Martínez, J. y A. Fernández Bremauntz. (comps.). Cambio climático: 
Una visión desde México. Secretaría de Medio Ambiente y Recursos NaturalesInstituto Nacional de Ecología. México, D.F., México. pp. 239-254.

Webster, G. L. y C. J. Bahre (eds.). 2001. Changing plant life of La Frontera. Observations on the vegetation in the United States/Mexico borderlands. Univ. New Mexico Press. Albuquerque, USA. xi $+260 \mathrm{pp}$.

Wehenkel, C. y C. Saenz-Romero. 2012. Estimating genetic erosion using the example of Picea chihuahuana Martínez. Tree Genetics and Genomes 1-10. DOI: 10.1007/ s11295-012-0488-5.

White, S. S. 1948. The vegetation and flora of the region of the Río Bavispe in northeastern Sonora, Mexico. Lloydia 11: 229-302. 


\section{APÉNDICE 1}

Regiones terrestres prioritarias de México (Arriaga et al., 2000) que se localizan de manera total o parcial en la Sierra Madre Occidental, incluyendo el Archipielago Madrense (AM).

\begin{tabular}{|c|c|}
\hline Región & Entidad \\
\hline 23. San Juan de Camarones & Durango, Sinaloa \\
\hline 24. Río Humaya & Durango, Sinaloa \\
\hline 25. San José & Sinaloa \\
\hline 26. Guadalupe y Calvo-Mohinora & Chihuahua, Durango \\
\hline 27. Barranca Sinforosa & Chihuahua \\
\hline 28. Rocahuachi-Nanaruchi & Chihuahua \\
\hline 29. Lago Los Mexicanos & Chihuahua \\
\hline 30. Alta Tarahumara-Barrancas & Chihuahua \\
\hline 31. Sierra Álamos-El Cuchujaqui & Chihuahua, Sonora \\
\hline 32. Cañón de Chínipas & Chihuahua, Sonora \\
\hline 33. Bassaseachic & Chihuahua \\
\hline 34. Babícora & Chihuahua \\
\hline 35. Cuenca del río Chico-Sirupa & Chihuahua \\
\hline 36. Yécora-El Reparo & Chihuahua, Sonora \\
\hline 41. Cananea-San Pedro & Sonora (AM) \\
\hline 42. Sierras Los Ajos-Buenos Aires-La Púrica & Sonora (AM) \\
\hline 43. Sahuaripa & Sonora \\
\hline 44. Bavispe-El Tigre & Sonora \\
\hline 45. Sierra de San Luis-Janos & Chihuahua, Sonora \\
\hline 46. Pastizales del norte del río Santa María & Chihuahua \\
\hline 47. Sierra del Nido-Pastizal de Flores Magón & Chihuahua \\
\hline 53. Cuchillas de la Zarca & Durango \\
\hline 54. Santiaguillo - Promontorio & Durango \\
\hline 55. Río Presidio & Durango, Sinaloa \\
\hline 56. Pueblo Nuevo & Durango \\
\hline 57. Guacamayita & Durango \\
\hline 58. La Michilía & Durango \\
\hline 59. Cuenca del río Jesús María & Durango, Jalisco, Nayarit, Zacatecas \\
\hline 60. Sierra Los Huicholes & Jalisco, Nayarit \\
\hline 65. Sierra de Morones & Zacatecas \\
\hline 66. Sierra Fría & Aguascalientes, Zacatecas \\
\hline 67. Sierra de Órganos & Durango, Zacatecas \\
\hline
\end{tabular}




\section{APÉNDICE 2}

Especies de gimnospermas leñosas, Ericaceae y Fagaceae, de la Sierra Madre Occidental y su distribución por regiones. $\mathrm{AM}=$ Archipiélago Madrense; $\mathrm{MN}=$ Madrense norte; $\mathrm{MC}=$ Madrense centro; $\mathrm{MS}=$ Madrense sur; $\mathrm{MX}=$ Madrense xerófila, MT $=$ Madrense tropical; $\mathrm{T}=$ Tropical .

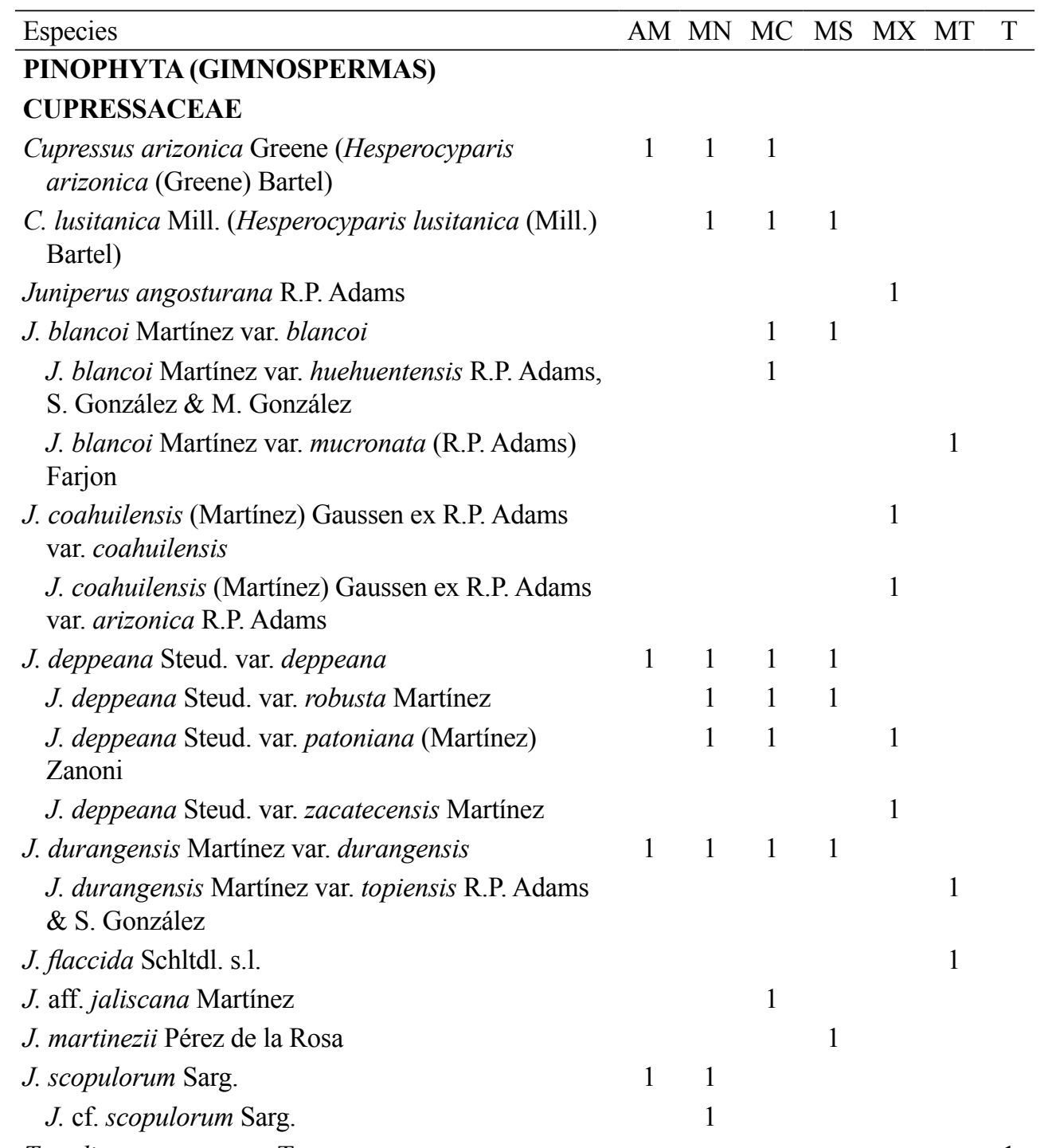

Taxodium mucronatum Ten. 
Apéndice 2. Continuación.

\begin{tabular}{lcccc}
\hline Especies & AM & MN & MC & MS \\
\hline PINACEAE & & & & \\
Abies concolor (Gordon \& Glend.) Lindl. & 1 & & & \\
Abies durangensis Martínez & & 1 & 1 & 1 \\
A. neodurangensis Debreczy, I. Rácz \& Salazar & & 1 & \\
Abies sp. & 1 & & \\
Picea chihuahuana Martínez & 1 & 1 \\
P. engelmannii subsp. mexicana (Martínez) P. & & 1
\end{tabular}

Schmidt

Pinus arizonica Engelm.

P. cembroides Zucc.

P. chihuahuana Engelm.

P. cooperi C.E. Blanco var. cooperi

P. cooperi C.E. Blanco var. ornelasii C.E. Blanco

P. devoniana Lindl.

P. discolor Bailey \& Hawksw.

P. douglasiana Martínez

$1 \quad 1 \quad 1$

P. durangensis Martínez

P. durangensis Martínez f. quinquefoliata Martínez

P. engelmannii Carr. var. engelmannii

P. flexilis E. James ssp. reflexa (Engelm.) A.E. Murray $\quad 1 \quad 1$

$P$. herrerae Martínez

P. leiophylla Schltdl. \& Cham.

P. lumholtzii B.L. Rob. \& Fernald

$\begin{array}{lll}1 & 1 & 1\end{array}$

$P$. luzmariae Pérez de la Rosa

$P$. maximartinezii Rzed.

P. maximinoi H.E. Moore

P. montezumae Lamb.

P. oocarpa Schiede ex Schltdl.

$\begin{array}{llll}P \text {. ponderosa Douglas ex Lawson \& C. Lawson var. } & & 1 & 1\end{array}$ scopulorum Engelm.

P. praetermissa Styles \& McVaugh

P. pseudostrobus Lindl. var. pseudostrobus Lindl.

P. strobiformis Engelm.

P. teocote Schltdl. \& Cham. 
Apéndice 2. Continuación.

\begin{tabular}{|c|c|c|c|c|c|c|c|}
\hline Especies & $\mathrm{AM}$ & $\mathrm{MN}$ & $\mathrm{MC}$ & MS & MX & MT & $\mathrm{T}$ \\
\hline P. yecorensis Debreczy \& I. Rácz & & 1 & & & & 1 & \\
\hline $\begin{array}{l}\text { Pseudotsuga menziesii (Mirb.) Franco var. glauca } \\
\text { (Mayr) Franco }\end{array}$ & 1 & 1 & 1 & 1 & & & \\
\hline
\end{tabular}

\section{MAGNOLIOPHYTA (ANGIOSPERMAS)}

\section{ERICACEAE}

Agarista mexicana (Hemsl.) Judd var. pinetorum

(Standl.\& Williams) Judd

Arbutus arizonica (A. Gray) Sarg.

A. bicolor S. González, M. González \& P.D. Sorensen

A. madrensis S. González

A. mollis $\mathrm{HBK}$.

A. occidentalis McVaugh \& Rosatti

A. tessellata P.D. Sorensen

A. tessellata P.D. Sorensen f. repens

A. xalapensis HBK. var. texana (Buckley) A. Gray

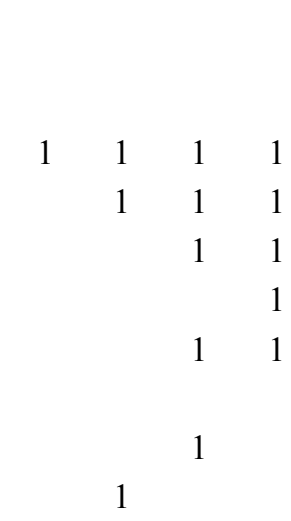

A. xalapensis HBK. var. xalapensis

A. xalapensis HBK. f. glandulosa M. Martens \&

Galeotti

Arctostaphylos pungens HBK.

Bejaria aestuans L.

Comarostaphylis cf. discolor (Hooker) Diggs 1

C. cf. discolor (Hooker) Diggs 2

C. glaucescens (HBK.) Zucc. ex Klotzsch

C. aff. lanata Small

C. polifolia (HBK.) Zucc. ex Klotzsch subsp. polifolia

$\begin{array}{lllll}1 & 1 & 1 & 1 & 1\end{array}$

Gaultheria erecta Vent.

G. glaucifolia Hemsl. var. glaucifolia

G. glaucifolia Hemsl. var. rosei (Small) Luteyn

Pernettya prostrata (Cav.) DC.

Vaccinium caespitosum Michx.

$V$. chihuahuense Wilbur \& Luteyn

$V$. confertum HBK.

$V$. geminiflorum HBK. 
Apéndice 2. Continuación.

\begin{tabular}{|c|c|c|c|c|c|c|c|}
\hline Especies & AM & $\mathrm{MN}$ & $\mathrm{MC}$ & MS & MX & MT & $\mathrm{T}$ \\
\hline
\end{tabular}

\section{FAGACEAE}

Quercus acutifolia Née

Q. albocincta Trel.

Q. aristata Hook. \& Arn.

Q. arizonica Sarg.

Q. x basaseachicensis C.H. Mull.

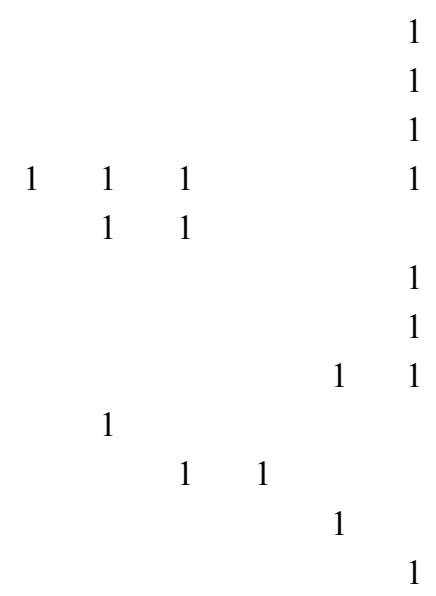

Q. candicans Née

Q. castanea Née

Q. chihuahuensis Trel.

Q. chrysolepis Liebm.

Q. convallata Trel.

Q. conzattii Trel.

Q. crassifolia Humb. \& Bonpl. var. crassifolia

(Trel.) E.F. Warb.

Q. crassipes Humb. \& Bonpl.

$Q$. depressipes Trel.

Q. durifolia Seem.

$1 \quad 1$

Q. eduardii Trel.

1

Q. elliptica Née

Q. emoryi Torr.

Q. fulva Liebm.

Q. gambelii Nutt

Q. gentryi C.H. Müll.

Q. glaucescens Humb. \& Bonpl.

Q. grisea Liebm.

Q. hartwegii Benth.

Q. hypoleucoides A. Camus

Q. jonesii Trel.

$Q$. laeta Liebm.

Q. laurina Humb. \& Bonpl.

Q. laxa Liebm.

Q. magnoliifolia Née 
Apéndice 2. Continuación.

\begin{tabular}{|c|c|c|c|c|c|c|c|}
\hline Especies & $\mathrm{AM}$ & $\mathrm{MN}$ & $\mathrm{MC}$ & MS & MX & MT & $\mathrm{T}$ \\
\hline Q. mcvaughii Spellenb. & 1 & 1 & 1 & & & 1 & \\
\hline Q. oblongifolia Torr. & 1 & & & & 1 & 1 & \\
\hline Q. obtusata Humb. \& Bonpl. & & & & & & 1 & \\
\hline Q. perpallida Trel. & & & & & 1 & & \\
\hline Q. potosina Trel. & & & 1 & 1 & & & \\
\hline Q. planipocula Trel. & & & & & & 1 & \\
\hline Q. praeco Trel. & & & & & & 1 & \\
\hline Q. praineana Trel. & & & 1 & 1 & & & \\
\hline Q. pungens Liebm. & 1 & & & & 1 & & \\
\hline Q. radiata Trel. & & & 1 & 1 & & & \\
\hline Q. resinosa Liebm. & & & & & & 1 & \\
\hline Q. rugosa Née & 1 & 1 & 1 & 1 & & & \\
\hline Q. scytophylla Liebm. & & & & & & 1 & \\
\hline Q. sideroxyla Humb. \& Bonpl. & & 1 & 1 & 1 & & & \\
\hline Q. splendens Née & & & & & & 1 & \\
\hline Q. striatula Trel. & & & 1 & 1 & & & \\
\hline Q. subspathulata Trel. & & & & & & 1 & \\
\hline Q. tarahumara Spellenb., Bacon \& Breedlove & & 1 & 1 & & & 1 & \\
\hline Q. toumeyi Sarg. & 1 & & & & 1 & & \\
\hline Q. tuberculata Liebm. & & & & & & 1 & \\
\hline Q. turbinella Greene & 1 & & & & 1 & & \\
\hline Q. undata Trel. & & & & & 1 & & \\
\hline Q. urbanii Trel. & & & & & & 1 & \\
\hline Q. x knoblochii C.H. Muller & & & & & & 1 & \\
\hline Q. x undulata Torr. & & & & & 1 & & \\
\hline Q. viminea Trel. & 1 & 1 & & & & 1 & \\
\hline
\end{tabular}




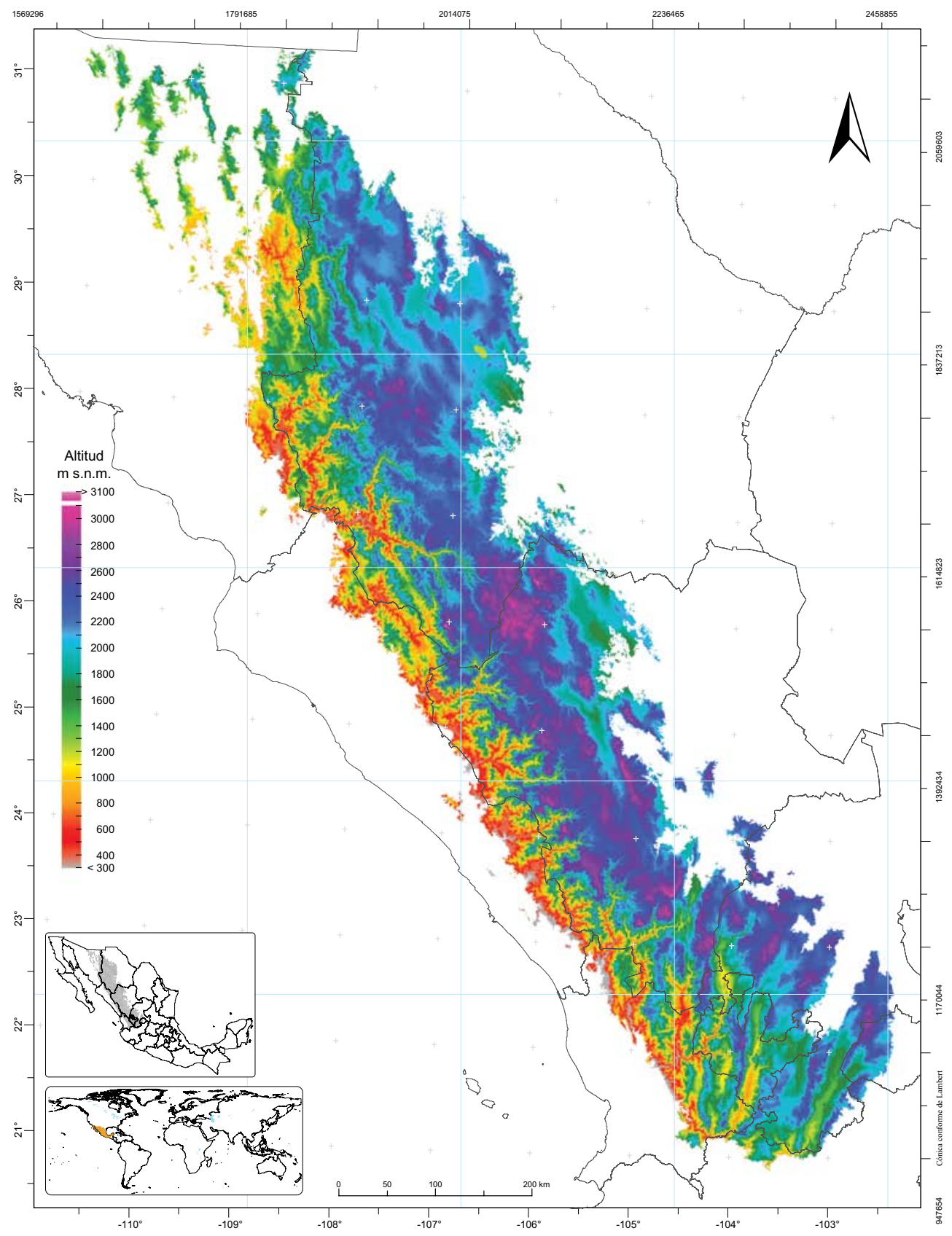

Fig. 1. Localización y elevaciones de la Sierra Madre Occidental. Fuente: Instituto Nacional de Estadística y Geografia. 2003. Modelo digital de elevación. Continuo de Elevaciones Mexicano CEM (2.0). 


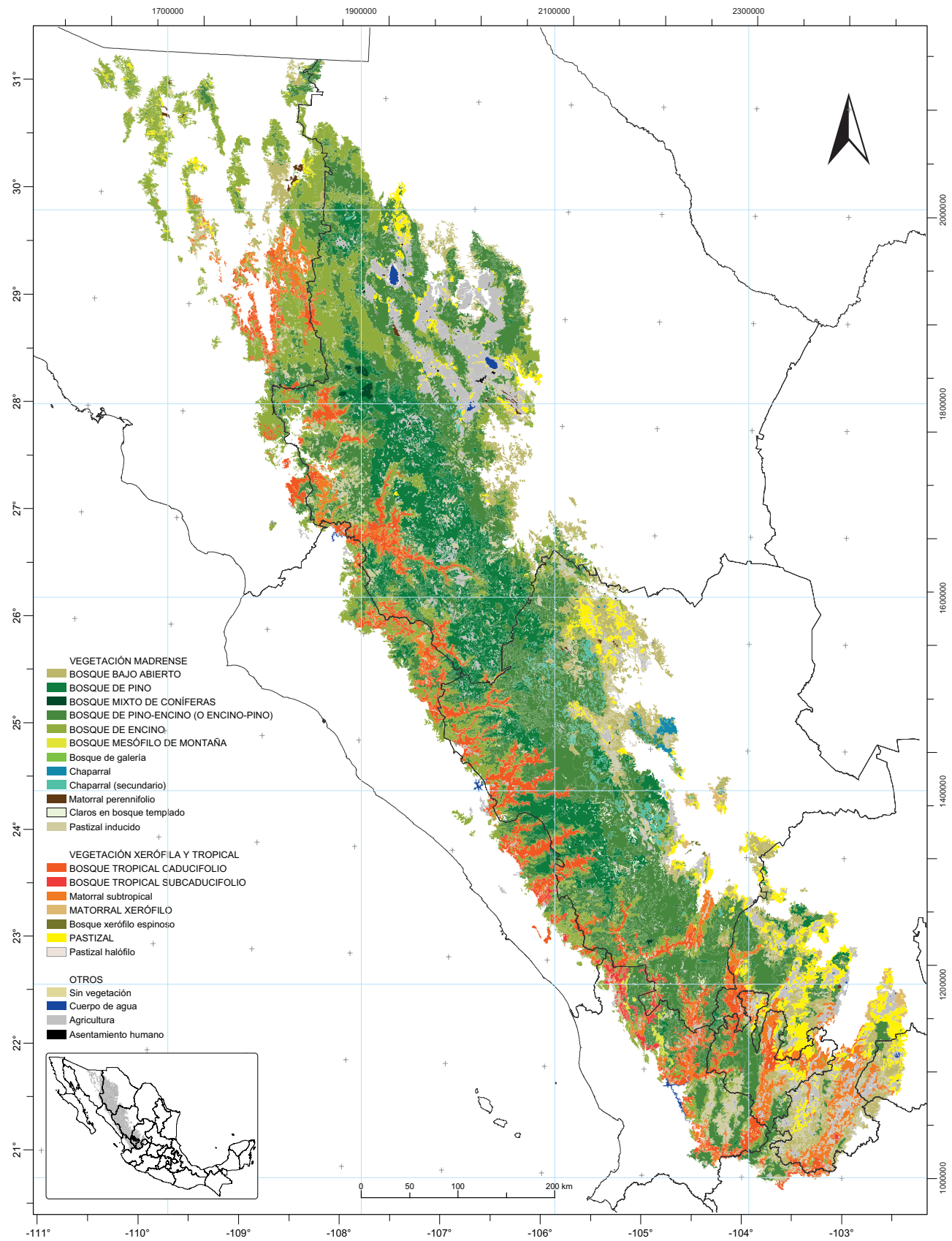

Fig. 2. Vegetación y uso del suelo en la Sierra Madre Occidental. Modificado de Instituto Nacional de Estadística y Geografia. 2002. Conjunto de datos vectoriales del Continuo Nacional de Uso del Suelo y Vegetación escala 1:250 000, Serie III. 